\title{
The Use of Ground-Based GPS Precipitable Water Measurements over China to Assess Radiosonde and ERA-Interim Moisture Trends and Errors from 1999 to $2015^{\circ}$
}

\author{
WeIXING ZHANG,,${ }^{\mathrm{a}, \mathrm{b}, \mathrm{c}}$ YIDONG LOU, ${ }^{\mathrm{a}, \mathrm{d}}$ JENNIFER S. HAASE, ${ }^{\mathrm{c}}$ RUI ZHANG, ${ }^{\mathrm{e}}$ GANG ZHENG, \\ JiNFANG HUANG, ${ }^{a}$ CHUANG SHI, ${ }^{\text {fa }}$ AND JiNGNAN LiU ${ }^{a}$ \\ ${ }^{a}$ Global Navigation Satellite Systems Research Center, Wuhan University, Wuhan, China \\ ${ }^{\mathrm{b}}$ School of Geodesy and Geomatics, Wuhan University, Wuhan, China \\ ${ }^{\mathrm{c}}$ Scripps Institution of Oceanography, University of California, San Diego, San Diego, California \\ ${ }^{\mathrm{d}}$ Collaborative Innovation Center of Geospatial Technology, Wuhan University, Wuhan, China \\ ${ }^{\mathrm{e}}$ National Earthquake Infrastructure Service, Beijing, China \\ ${ }^{\mathrm{f}}$ School of Electronic and Information Engineering, Beihang University, Beijing, China
}

(Manuscript received 11 August 2016, in final form 1 June 2017)

\begin{abstract}
Global positioning system (GPS) data from over 260 ground-based permanent stations in China covering the period from 1 March 1999 to 30 April 2015 were used to estimate precipitable water (PW) above each site with an accuracy of about $0.75 \mathrm{~mm}$. Four types of radiosondes (referred to as GZZ2, GTS1, GTS1-1, and GTS1-2) were used in China during this period. Instrumentation type changes in radiosonde records were identified by comparing PW calculated from GPS and radiosonde data. Systematic errors in different radiosonde types introduced significant biases to the estimated PW trends at stations where more than one radiosonde type was used. Estimating PW trends from reanalysis products (ERA-Interim), which assimilate the unadjusted radiosonde humidity data, resulted in an artificial downward PW trend at almost all stations in China. The statistically significant GPS PW trends are predominantly positive, consistent in sign with the increase in moisture expected from the Clausius-Clapeyron relation due to a global temperature increase. The standard deviations of the differences between ERA-Interim and GPS PW in the summer were 3 times larger than the observational error of GPS PW, suggesting that potentially significant improvements to the reanalysis could be achieved by assimilating denser GPS PW observations over China. This work, based on an entirely independent GPS PW dataset, confirms previously reported significant differences in radiosonde PW trends when using corrected data. Furthermore, the dense geographical coverage of the all-weather GPS PW observations, especially in remote areas in western China, provides a valuable resource for calibrating regional trends in reanalysis products.
\end{abstract}

\section{Introduction}

As the most abundant greenhouse gas, water vapor plays a key role in the global energy and hydrologic cycle (Kiehl and Trenberth 1997). According to the ClausiusClapeyron equation, an increase of $1 \mathrm{~K}$ in atmospheric temperature will cause an increase of about $7 \%$ in water content if relative humidity is assumed to remain constant, which in turn will significantly enhance the

Supplemental information related to this paper is available at the Journals Online website: http://dx.doi.org/10.1175/ JCLI-D-16-0591.s1.

Corresponding author: Chuang Shi, shi@whu.edu.cn warming (Trenberth et al. 2003). The strong positive feedback associated with increased water vapor greatly affects global climate (IPCC 1996). Accurate knowledge of the distribution and variability of water vapor is indispensable to climate change research and weather forecasting.

Great efforts have been made in recent decades to measure trends in atmospheric water vapor due to climate change using different methods. Among these, radiosonde data have the longest records and have been most widely used (Bannon and Steel 1960). They have near-global distribution over land and high vertical resolution but suffer from an inhomogeneity problem due to changes in instrument types, observational practice, calibration and processing strategies, station 
relocation, or other issues (Zhai and Eskridge 1996; Zhao et al. 2012). This inhomogeneity can induce serious biases in the long-term climate trends (e.g., Elliott and Gaffen 1991; Wang et al. 2003). For humidity data in radiosonde records, which are the focus of this study, several methods have been developed to detect and correct the records, for example, by intercomparing with other nearby radiosonde stations (Parker and Cox 1995; Durre et al. 2009) or with a cryogenic frostpoint hygrometer (Miloshevich et al. 2001; Vömel et al. 2007). Statistical approaches were also developed for this purpose, such as the Easterling-Peterson (E-P) method (Easterling and Peterson 1995), which detects discontinuities in the difference time series between a candidate temperature record and a group of reference temperature records using multiphase regression analysis, and the recent method proposed by Dai et al. (2011), to detect discontinuities in the occurrence frequency of binned dewpoint depression. However, the intercomparison methods are somewhat limited due to ambiguity with respect to reference station data quality or their dependence on other data sources that are not always readily available, such as nearby simultaneous radiosonde launches with reference frostpoint hygrometer observations or specifically calibrated radiosonde types such as the Vaisala models RS80-A and RS92. Dai et al. (2011), on the other hand, use a statistical method to detect changes, subject to specific assumptions that the cumulative distribution function differences before and after changepoints are entirely caused by nonclimatic changes.

Passive infrared radiometers can also be used to measure water vapor, but they require clear-sky conditions (Rocken et al. 1995; Divakarla et al. 2006). Satellite microwave radiometers, for example the Special Sensor Microwave Imager (SSM/I), are insensitive to cloud coverage and can provide high-accuracy water vapor measurements over the ocean (Sun 1993). However, an assumption about surface emissivity has to be made in the water vapor retrievals, which makes it less accurate over land due to variations in surface conditions (Deeter 2007; Vey et al. 2010). Global positioning system (GPS) radio occultation (RO) can be used to retrieve highaccuracy humidity information in the upper troposphere regardless of the cloud coverage or the surface conditions (Hajj et al. 2004; Liou et al. 2005). Unfortunately, the RO signal does not always penetrate into the lowest part of the troposphere near Earth's surface, which contains most of the water vapor in the atmosphere.

Ground-based GPS has been proven to be an accurate and useful method for water vapor remote sensing, with the advantages of low cost, automation, all weather operations, high temporal resolution, and, most important, homogeneity over the long term (Bevis et al. 1992). Precipitable water (PW), which represents the total atmospheric water vapor contained in a vertical column of unit cross-sectional area of the atmosphere, can be retrieved from propagation delays in the GPS signals recorded at ground-based permanent GPS receivers at the same level of accuracy as radiosondes and radiometers (Elgered et al. 1997; Emardson et al. 1998; Haase et al. 2003). As an independent data source, ground-based GPS PW has been used to identify and quantify errors in radiosonde data (e.g., Wang and Zhang 2008), to improve numerical weather prediction (NWP) forecasts (e.g., Smith et al. 2000; Vedel et al. 2004; Poli et al. 2007), and for climatological investigations (Nilsson and Elgered 2008).

Model reanalyses, where many kinds of observations are reanalyzed with advanced data-assimilation techniques, provide a multivariate, spatially complete, and coherent record of the global atmospheric circulation (Bengtsson et al. 2004; Dessler and Davis 2010; Dee et al. 2011). However, as an important input data source, if the inhomogeneity and biases existing in radiosonde humidity observations have not been appropriately adjusted before their assimilation into the published reanalysis products, the errors will induce significant systematic biases and spurious changes in long-term water vapor trends.

The climatic variations in China are associated with a wide range of spatial scales, complex topographic conditions (including the Tibetan Plateau), teleconnections with El Niño-Southern Oscillation (Lau 1992; Wang et al. 2000), and the influence of the East Asian monsoon (Ding 1994). Radiosonde humidity data from stations in China have been included in several previous Northern Hemispheric water vapor trend analyses (Ross and Elliott 2001; Durre et al. 2009). In particular, Zhai and Eskridge (1997) investigated the PW trend over China over the period from 1970 to 1990 based on 44 radiosonde stations selected based on a homogeneity test. The PW trends were found to be closely correlated with precipitation and surface temperature. More recently, Zhao et al. (2012) and Zhao et al. (2015) studied the humidity trends over China for 1970-2008 and 19702012, respectively, by using radiosonde data homogenized with the method proposed by Dai et al. (2011). After the homogenization, positive PW trends of $1 \%$ $5 \%$ decade $^{-1}$ were seen across most of China.

Ground-based GPS water vapor measurements have also been used to assess errors in other datasets. In one example, PW data from six GPS stations for more than one year were calculated in order to assess errors in radiosonde and NWP models over the Tibetan Plateau 
(Liu et al. 2005). Results showed that the radiosonde measurements and NWP over the Tibetan Plateau may suffer from significant dry biases. In Wang and Zhang (2008), PW from 1997 to 2006 is estimated for more than 300 global International Global Navigation Satellite Systems (GNSS) Service (IGS) stations, including five stations in China, and the systematic errors in 14 radiosonde types (including the types Shang-M and Shang-E used in China) are assessed by comparisons with GPS data. Jin et al. (2008) investigated the multiscale variations of PW over China based on more than 20 permanent GPS stations from 2004 to 2007 and found that the dominant seasonal and diurnal variations depend on geographic location and topographic features.

The old type 59-701 mechanical radiosonde (referred to as GZZ2 hereafter, also named Shang-M in some published studies) has been used for decades in China, with a goldbeater's skin hygrometer equipped for humidity measurement. Because of the slow response and low precision of the GZZ2, a new-generation L-band digital electronic radiosonde system has been deployed in recent years ( $\mathrm{Li}$ 2010). The new radiosonde system manufactured by Shanghai Changwang Meteorological Instrument Plant (referred as GTS1, also named Shang-E in some published studies) was deployed and is currently used by most upper-air sounding stations in China. The newly added GTS1-1 and GTS1-2 radiosondes manufactured by Taiyuan Meteorological Instrument Plant and Nanjing Bridge Machinery Company, respectively, have been used in some of the stations in China since 2010. GTS1 and GTS1-1 are both equipped with carbon hygristor sensors while GTS1-2 uses a thin-film capacitor as the humidity sensor.

In this study, GPS data from the Crustal Movement Observation Network of China (CMONOC), including approximately 28 stations starting in 1999 and over 260 stations operational from 2011 to 2015 in mainland China, have been processed based on the precise point positioning (PPP) method (Zumberge et al. 1997). Special efforts have been made to acquire reliable atmospheric station pressures at GPS stations by selecting from measurements from ground-based GPS station meteorological observations, nearby synoptic station observations, and reanalysis products. The retrieved long time series of homogenous PW with wide spatial extent over China will be used to assess radiosonde humidity data errors. Most of the current radiosonde error analyses to date have focused on radiosondes from Vaisala and VIZ while only a few assessed the performance of radiosonde types used in China. In Wang and Zhang (2008), only five GPS stations were included in a systematic error analysis of two radiosonde types (Shang-M and Shang-E) in China and these two types were not treated separately in spite of their significant differences (as will be shown later). Liang et al. (2012) tried to quantify errors of two radiosonde types (GZZ2 and GTS1) with only two GPS stations (one station from 1999 to 2008 and one station in 2003) on the Tibetan Plateau. The objective of this paper is to determine the systematic errors existing in all Chinese radiosonde types used from 1999 to 2015 and to investigate the influences on PW trends. The accuracy of water vapor derived from reanalyses will also be assessed by comparisons with GPS over China.

The paper is organized as follows: data used in this paper, including GPS data, radiosonde data, and reanalysis data will be described in section 2 . Section 3 will focus on the estimation of PW and the corresponding error analysis. Radiosonde data and reanalysis products will be compared with GPS data to assess the errors and the corresponding influences on the PW trends in sections 4 and 5, respectively, followed by a discussion of the results compared to previous work in section 6 , and the final conclusions in section 7 .

\section{Data and methodology}

\section{a. GPS data}

The CMONOC in China maintains operational permanent GPS stations for crustal deformation monitoring, earthquake research, and space environment and meteorological research. From 1999 to mid-2010, which is called phase I, there were approximately 27 permanent GPS stations distributed over China. The network was then dramatically extended in phase II at the end of 2010. By 2015, more than 260 permanent stations were in operation in China. The rapid growth in the geographical distribution and number of stations is seen from 2010 to 2011 in Figs. 1a and 1b, respectively. Six stations in the network also belong to the IGS network, denoted with red triangles in Fig. 1a, and will be used as a baseline for consistency with other analysis of the position and atmospheric parameters.

All GPS measurements sampled at $30 \mathrm{~s}$ from 1 March 1999 to 30 April 2015 are processed by the PPP method in a daily manner using the position and navigation data analyst (PANDA) package (Shi et al. 2008) developed at Wuhan University. The final satellite orbit and clock products from 1999 to 2015 provided by one of the IGS data analysis centers, the Massachusetts Institute of Technology (MIT), are used and fixed in the PPP method because they have been reprocessed in the reference frame called IGS08 (Rebischung et al. 2012) for the entire period, in order to avoid any inconsistence in satellite orbit products within different reference frames released by IGS during different periods. Differential 


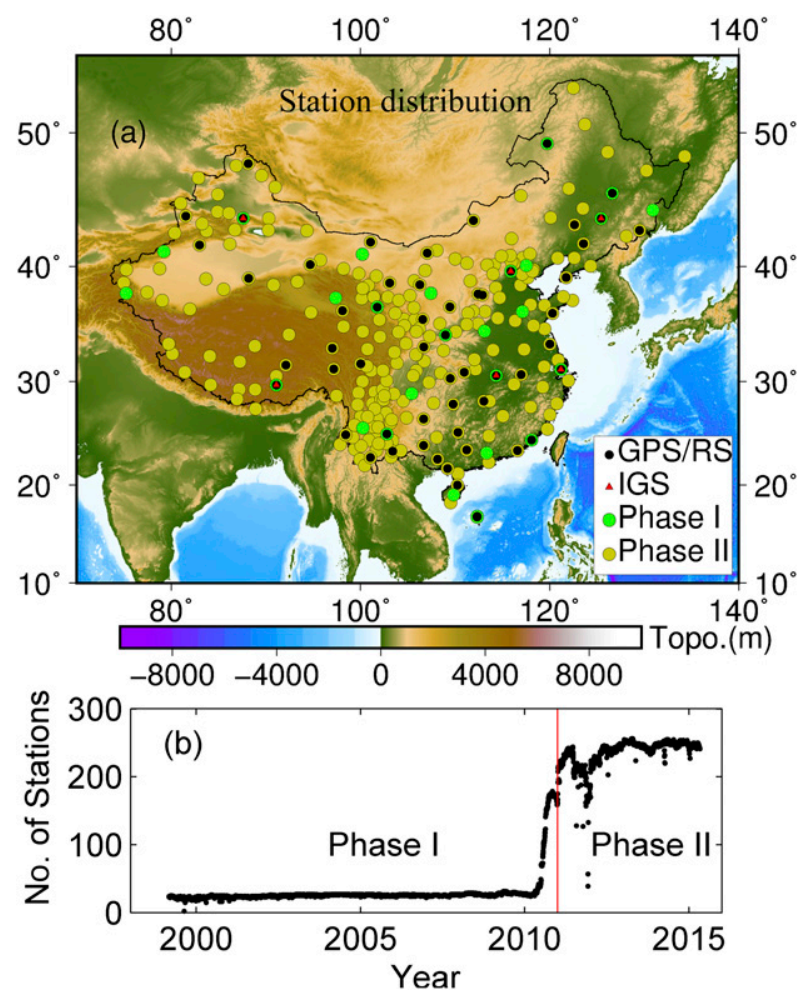

FIG. 1. (a) GPS station geographical distribution. Green and yellow dots denote stations operated starting in phases I and II, respectively. Red triangles are stations that also belong to the IGS network and black dots represent GPS stations with nearby radiosonde stations (denoted as RS) (b) Number of available GPS stations used in this study. The red vertical line denotes the beginning of phase II of the CMONOC project in 2011.

code biases between frequencies from the Center for Orbit Determination in Europe (CODE) are used (Schaer and Steigenberger 2006). The absolute antenna phase center correction model (Schmid et al. 2007), phase wind-up corrections (Wu et al. 1993), and relativity corrections are applied. Ionospheric delays are eliminated by using ionosphere-free combination of observations. Ground station coordinates are estimated as constants each day and receiver clocks are solved each epoch with errors taken as white noise. The station coordinates are determined from observations of the travel time to four or more satellites. The travel time depends on the refractive index of the atmosphere, which in turn depends on temperature, pressure, and water vapor. When solving for position, one must also solve for the refractive delay parameterized as the integrated zenith delay through a layer of atmosphere. The neutral atmosphere will cause a propagation delay along the signal path from the satellite to the receiver and can be divided into two components, namely the "wet" (caused by water vapor) and "hydrostatic" (as a result of atmospheric density) delays. GPS measurements are made along the line of sight from the receiver to the satellite, so mapping functions are usually used to map the slant delays into the zenith direction and account for first-order geometrical effects of refraction.

The empirical global pressure and temperature (GPT) model (Boehm et al. 2007) and relative humidity of $50 \%$ at mean sea level (MSL) are used to estimate the a priori zenith hydrostatic delays (ZHD) and a priori zenith wet delays (ZWD) in the GPS analysis. Corrections to the a priori ZWD are then estimated as piecewise constant every $2 \mathrm{~h}$ with a power density of $20 \mathrm{~mm} / \sqrt{h}$, where $h$ denotes time in hours, which can also include any mismodeling of the a priori ZHD. The final zenith tropospheric delays (ZTD) are retrieved by summing up the a priori ZHD, the a priori ZWD, and the estimated ZWD corrections. The relatively loose constraint on variability of $20 \mathrm{~mm} / \sqrt{h}$ is widely used in meteorological studies (Haase et al. 2003; Jin et al. 2007; Brenot et al. 2014). The global mapping function (GMF) (Boehm et al. 2006) based on the assumption of a climatological model of an azimuthally symmetric atmosphere is used in the processing. Tropospheric gradients in the north-south and east-west directions are estimated at 12-h intervals. Cutoff elevation angles are set to $7^{\circ}$ and an elevationdependent weighting strategy is applied to measurements at low elevations (below $30^{\circ}$ ) (Gendt et al. 2003) to reduce the influence of multipath and the uncertainties in mapping functions at low elevations. We apply quality control criteria to detect poorly constrained ZTD solutions to by discarding any ZTD estimate that is more than four standard deviations (STDs) from the monthly mean ZTD at the site.

After obtaining ZTD, the ZHD is subtracted to yield ZWD. Rather than using the a priori ZHD from the previous GPS data processing, a more accurate estimate of ZHD is calculated based on accurate surface station pressure $P_{s}$ (all pressures in $\mathrm{hPa}$ ) through the Saastamoinen model (Saastamoinen 1972; Elgered et al. 1991):

$$
\mathrm{ZHD}=(2.2779 \pm 0.0024) P_{s} / f(\varphi, H),
$$

Where $f(\varphi, H)=(1-0.00266 \cos 2 \varphi-0.00028 H)$ accounts for the variation of gravitational acceleration at ellipsoidal latitude $\varphi$ and the ellipsoidal height $H$ (in $\mathrm{km}$ ) of the GPS station.

The moisture weighted mean temperature $T_{m}$ is then used to calculate the conversion factor $Q$ to convert ZWD to PW (Bevis et al. 1992):

$$
\mathrm{PW}=\frac{1}{Q} \mathrm{ZWD}=\frac{1}{10^{-6} \rho_{w} R_{v}\left[\left(k_{3} / T_{m}\right)+k_{2}^{\prime}\right]} \mathrm{ZWD}
$$


where $\rho_{w}$ is liquid water density $\left(1000 \mathrm{~kg} \mathrm{~m}^{-3}\right), R_{v}$ denotes the specific gas constant of water vapor $\left(461.51 \mathrm{~J} \mathrm{~K}^{-1} \mathrm{~kg}^{-1}\right)$, and $k_{2}^{\prime}$ and $k_{3}$ are atmospheric refractivity constants $17 \pm 10 \mathrm{~K} \mathrm{hPa}^{-1}$ and $3.776 \pm 0.004 \times$ $10^{5} \mathrm{~K}^{2} \mathrm{hPa}^{-1}$, respectively. The term $T_{m}$ will be calculated from reanalysis products instead of using an empirical linear relationship between $T_{m}$ and the surface temperature (Bevis et al. 1992) for better accuracy (Wang et al. 2005). A detailed procedure of retrieving PW from GPS ZTD can be found in the supplemental material.

\section{b. Radiosonde data}

Radiosonde data provided by the Integrated Global Radiosonde Archive (IGRA) are used in this study (available online at https://www.ncdc.noaa.gov/dataaccess/weather-balloon/integrated-global-radiosondearchive) (Durre et al. 2006). There were about 150 radiosonde stations in China during the period from 1999 to 2015, with radiosonde balloons usually launched twice daily (at around 0000 and 1200 UTC). An additional six stations are contained in the Chinese Meteorological Agency (CMA) archive; however their time series are shorter so were not included (Zhao et al. 2012). The data quality control strategy we implement is similar to Wang and Zhang (2008). Radiosonde temperature and humidity profiles are required to reach at least $300 \mathrm{hPa}$ for the top level and have data available at the surface and at least five (four) standard pressure levels above the surface for stations below (above) $1000 \mathrm{hPa}$. In addition, profiles with large gaps (greater than $200 \mathrm{hPa}$ ) in pressure between consecutive recordings of temperature or humidity are rejected.

Radiosonde stations are generally not collocated with GPS stations. For this comparison, we require that the horizontal separation is less than $50 \mathrm{~km}$ and the elevation difference is less than $200 \mathrm{~m}$. There are a total of 58 matched pairs during the period from 1999 to 2015 in China and their geographic distribution is presented in Fig. 1a. Names and locations of all matched stations are listed in Table S1 in the supplemental material. The method described in Haase et al. (2003) is used for the altitude offset correction between GPS and radiosonde stations for temperature and relative humidity. That is, for GPS antenna levels above the lowermost radiosonde level, the temperature at the antenna level is estimated by linear interpolation, while for GPS antenna levels below the lowermost radiosonde level the temperature at the antenna level is estimated by linear extrapolation, assuming a constant temperature lapse rate of $-6.5 \mathrm{~K} \mathrm{~km}^{-1}$, and constant relative humidity of the value at the lowermost radiosonde level. The hydrostatic and ideal gas equations are used to adjust pressure to the GPS station height as described in Wang et al. (2007). Finally, PW from the GPS antenna level to the top of the radiosonde records is calculated by integration over height as described in the supplemental material.

\section{c. ERA-Interim}

ECMWF produces the most widely used global atmospheric reanalysis, ERA-Interim, covering the period from 1979 onward, with spatial resolution of approximately $80 \mathrm{~km}$ (T255 spectral resolution) on 60 vertical levels from 1000 to $0.1 \mathrm{hPa}$ (Dee et al. 2011; Gregow et al. 2015). As mentioned above, radiosonde observations are an important data source assimilated in the reanalysis but the moisture inhomogeneity for sites in China has not been corrected before assimilation (Zhao et al. 2015). The accuracy of PW from the ERA-Interim over China will be quantitatively assessed by comparisons with GPS data from 1999 to 2015. Daily fields (geopotential height, temperature, and specific humidity) on pressure levels are used in this study (data available online at http://apps. ecmwf.int/datasets/data/interim-full-daily). The field values at four grid points $p_{1}, p_{2}, p_{3}$, and $p_{4}$, nearest the GPS station latitude and longitude coordinates $(\varphi, \lambda)$, are horizontally interpolated to the position of GPS station at each pressure level by taking the weighted average of the gridpoint values, where the weights are given by the angular distance from each grid point (Jade and Vijayan 2008). After obtaining the variables at pressure levels at the horizontal location of the GPS antenna, the same altitude offset correction method is applied as was used for the radiosonde data to calculate PW from the GPS antenna level to the top level of ERA-Interim.

\section{d. Surface pressure estimation}

ZHD is a function of the station pressure $P_{s}$ at the GPS antenna height as shown in Eq. (1). Biases of $1 \mathrm{hPa}$ in $P_{s}$ can induce approximately 2-3-mm delay errors in ZHD, corresponding to about 0.5 -mm errors in the final PW (Hagemann et al. 2003). However, pressure measurements at CMONOC GPS stations are only available in phase II, namely after 2011, and the records are usually not continuous for most stations. Sometimes they are noisy (Wang et al. 2006) and require careful quality checks before use. For most stations the completeness (number of high-quality pressure measurements divided by number of ZTD measurements) is only about $60 \%-70 \%$ and there are more than 100 stations where it is less than $50 \%$. Therefore, alternate sources for pressure data are required (e.g., nearby synoptic station records and reanalysis products) in order to get more complete time series of $\mathrm{PW}$. The procedure adopted was to select the more complete synoptic station data as the source if it is closer to the observed pressure at the GPS site than to the station pressure 

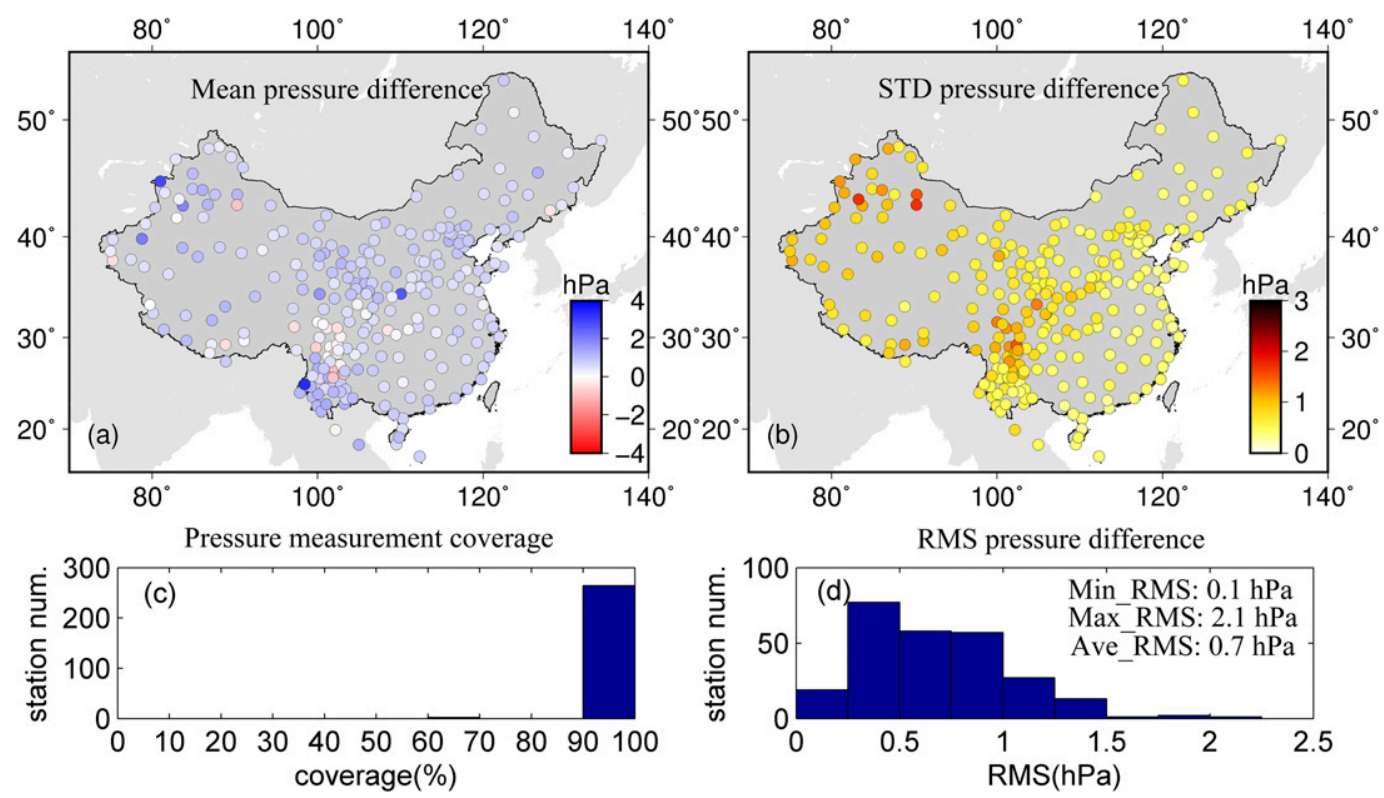

FIG. 2. (a) Geographic distribution of mean of station pressure differences (hPa; ERA-Interim minus GPS), (b) STD of station pressure differences, (c) histogram of combined pressure measurement completeness, and (d) histogram of RMS pressure difference (combined measurements minus GPS). The minimum, maximum, and average RMS (weighted by measurement numbers) are annotated in the top-right corner of (d).

from the ERA-Interim. Otherwise select ERA-Interim as the pressure source if the RMS difference from the GPS station pressure does not exceed $2.5 \mathrm{hPa}$. Finally, if the ERA-Interim RMS difference exceeds $2.5 \mathrm{hPa}$ use the GPS station pressure. Further details are provided in the supplemental material on how the combined pressure measurement dataset is constructed.

The sample rate for GPS station pressure measurements, synoptic station pressure records, and ERAInterim products is $30 \mathrm{~s}, 3 \mathrm{~h}$, and $6 \mathrm{~h}$, respectively. No temporal interpolation is used in this study, so the final pressures as well as other variables $\left(T_{m}\right.$ and $\left.\mathrm{PW}\right)$ are degraded to 6-h intervals at 0000, 0600, 1200, and 1800 UTC. The histogram of the final combined pressure measurement dataset completeness and the histogram of RMS pressure differences between the combined pressures and GPS station pressure measurements are shown in Figs. 2c and 2d, respectively. Stations with GPS pressures directly used will not be included in the RMS calculation. For most stations, the combined pressure measurements cover $90 \%-100 \%$ of the epochs and the RMS for most stations is from about 0.25 to $1 \mathrm{hPa}$, with minimum, maximum, and average RMS of $0.1,2.1$, and $0.7 \mathrm{hPa}$, respectively.

\section{GPS PW error analysis}

The main factors contributing to GPS PW observational errors consist of errors in ZTD, $P_{s}$, and $T_{m}$. In this section, the quality of the positions and ZTDs estimated by the PPP method will be assessed first based on six stations in CMONOC that also belong to the IGS network. The uncertainty in $T_{m}$, which is derived from ERAInterim, will be assessed by comparison with $T_{m}$ from radiosonde profiles. With the uncertainties of ZTD, $T_{m}$, and $P_{s}$, uncertainties of GPS PW will then be derived.

\section{a. Position and ZTD error analysis}

The correlation among PPP-method-estimated parameters is such that errors in vertical position can trade off with errors in ZTD. To estimate possible contributions to errors in ZTD, the daily position solutions of six stations that also belong to IGS network are compared with position solutions from IGS-reprocessed Solution Independent Exchange (SINEX) products (available online at ftp://cddis.gsfc.nasa.gov). IGS SINEX positions and IGS ZTD parameters are accepted as the most accurate reference because they combine estimates from several independent IGS Analysis Centers and have associated error estimates. The time series of position differences between our estimates and the IGS SINEX positions in the east, north, and upward components for these stations are presented in Fig. 3, left, and the statistical values of the differences are shown in Fig. 3, right. Gaps in the position difference time series are due to the absence of IGS SINEX solutions and/or GPS data. The mean values of position differences are smaller than $4 \mathrm{~mm}$ for all six stations in three 

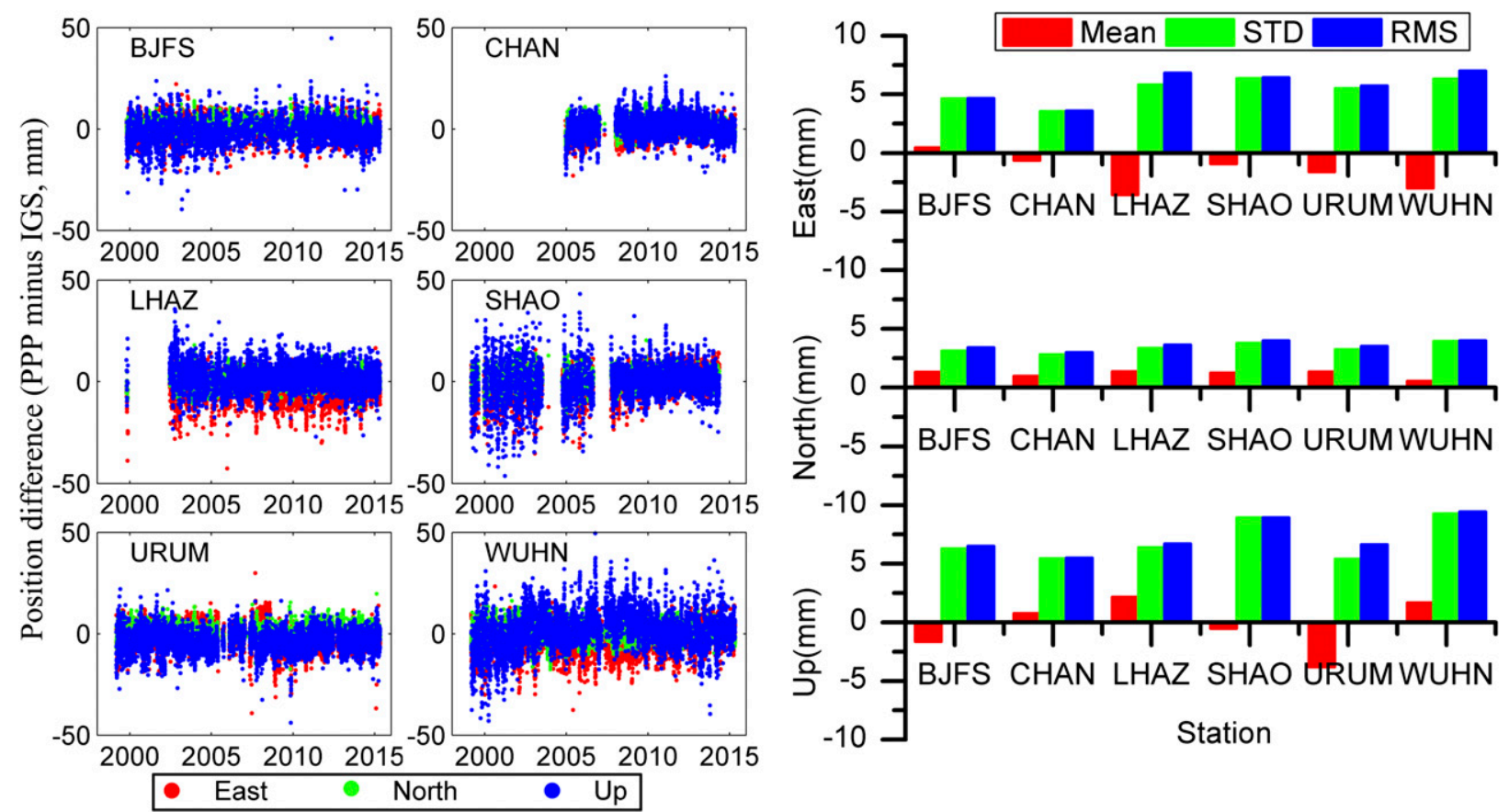

FIG. 3. Position comparisons with IGS SINEX solutions for six IGS stations: (left) time series of position differences (PPP method estimate minus IGS) for the east (red), north (green), and upward (blue) components and (right) statistical values of position differences for the three components.

components. RMS values are smaller than $10 \mathrm{~mm}$ with typical RMS of approximately 5.7,3.6, and $7.3 \mathrm{~mm}$ in the east, north, and upward component, respectively, which is in the same accuracy range as IGS SINEX position solutions, even including any small differences related to reference frames.

The estimated 2-hourly ZTD for the six IGS stations are also compared to the IGS ZTD products. ZTD estimates for periods when there are fewer than $50 \%$ of the expected GPS observations in a 2-h interval are excluded and an outlier check (monthly mean \pm 4 times standard deviation) is applied before the ZTD comparison and the later PW conversion. IGS ZTD products at 5-min sampling rate are averaged to a 2 -h interval to be comparable with the ZTD estimates in this study. Prior to 27 April 2011, IGS final ZTD products in the IGb05 reference frame are used in the comparison because ZTD products in International Terrestrial Reference Frame 2008 (ITRF2008) are not available. Time series of ZTD differences for six IGS stations are presented in Fig. 4. There is no observable difference in the time series before and after 27 April 2011, so differences among reference frames IGb05, ITRF2008, and IGS08 were neglected in the ZTD comparisons. (Note that the reference frame IGS08 is consistently used in our PPP-method processing so there are no reference frame inconsistencies in the data used in the rest of the paper). As can be seen from the right panel of Fig. 4, mean differences are smaller than $2 \mathrm{~mm}$ in ZTD for all six stations and the typical RMS is approximately $3.9 \mathrm{~mm}$ with minimum and maximum values of 2.7 and $4.6 \mathrm{~mm}$, respectively, which is comparable to the nominal uncertainty reported for IGS final ZTD products ( $\sim 4 \mathrm{~mm}$; http://www.igs.org/products). Since most stations in CMONOC were equipped with the same receiver and antenna type and the same GPS data processing strategy was applied, we can expect typical stations to be of this quality.

\section{b. The $T_{m}$ error analysis}

The term $T_{m}$ is a key parameter used in the retrieval of PW from ZWD. One way to estimate $T_{m}$ at GPS stations is based on a linear empirical relationship between surface temperature and $T_{m}$ (Bevis et al. 1992). However, underestimation of $T_{m}$ by as much as $6 \mathrm{~K}$ in the tropics and subtropics and overestimation by up to $5 \mathrm{~K}$ in the middle and high latitudes were found with this linear relationship (Wang et al. 2005). We use reanalysis products to derive $T_{m}$ at GPS stations, which can have global accuracy better than $2 \mathrm{~K}$ (Wang et al. 2005), and assess the accuracy of this approach using radiosondes. The values of $T_{m}$ at 153 radiosonde stations in China from 1999 to 2015 are calculated as described in section 2b. Then $T_{m}$ is estimated from ERA-Interim products at these locations using the interpolation method 

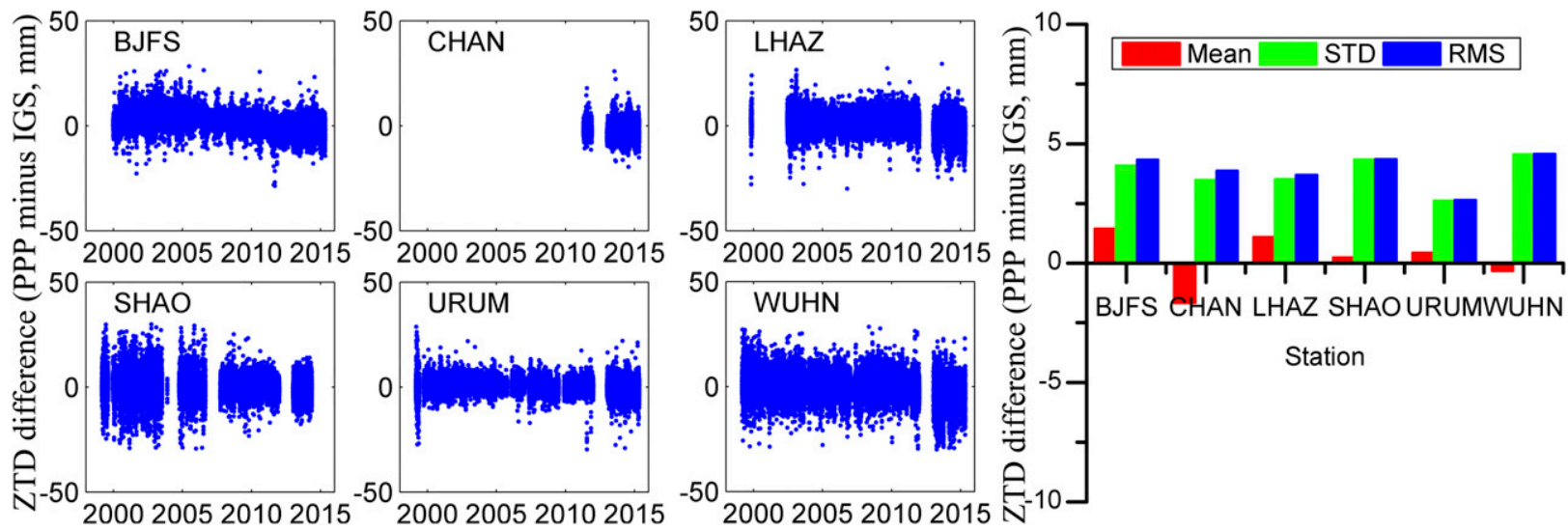

FIG. 4. ZTD comparison with IGS final ZTD products for six IGS stations: (left) time series of ZTD differences (PPP estimate minus IGS) and (right) statistical values of ZTD differences.

described in section 2c. The geographic distribution of the RMS $T_{m}$ difference between radiosondes and ERAInterim and the histogram is presented in Fig. 5. The RMS for most stations in southeastern China is smaller than $2 \mathrm{~K}$ and for most of stations in other regions is approximately $2-3 \mathrm{~K}$. The typical RMS is approximately $1.8 \mathrm{~K}$.

\section{c. PW error analysis}

In spite of quality controls in ZTD, $P_{s}$, and $T_{m}$, there may still be outliers in the PW time series.
Similarly, a range limit check and an outlier check are applied to PW time series at each GPS station. PW values smaller than $0 \mathrm{~mm}$ are removed in the limit check, which excludes approximately $0.19 \%$ of data points. In the outlier check, PW values that differ from the monthly mean value by more than 4 times the monthly standard deviation are rejected, which excludes approximately $0.22 \%$ of the data points.

Similar to the method used in Ning et al. (2016), the PW errors can be estimated by

$$
\sigma_{\mathrm{PW}}=\sqrt{\left(\frac{\sigma_{\mathrm{ZTD}}}{Q}\right)^{2}+\left[\frac{2.2779 \sigma_{P_{s}}}{f(\varphi, H) Q}\right]^{2}+\left[\frac{P_{s} \sigma_{c}}{f(\varphi, H) Q}\right]^{2}+\left(\mathrm{PW} \frac{\sigma_{Q}}{Q}\right)^{2}},
$$

where $\sigma_{\mathrm{ZTD}}, \sigma_{P_{s}}$, and $\sigma_{Q}$ denote the uncertainties of $\mathrm{ZTD}, P_{s}$, and $Q$, respectively. The function $f(\varphi, H)$ can be simply taken as 1 in Eq. (3). Also, $\sigma_{c}$ is the uncertainty of the constant shown in Eq. (1), which equals 0.0024 , and $\sigma_{Q}$ can be expressed as (Ning et al. 2016)
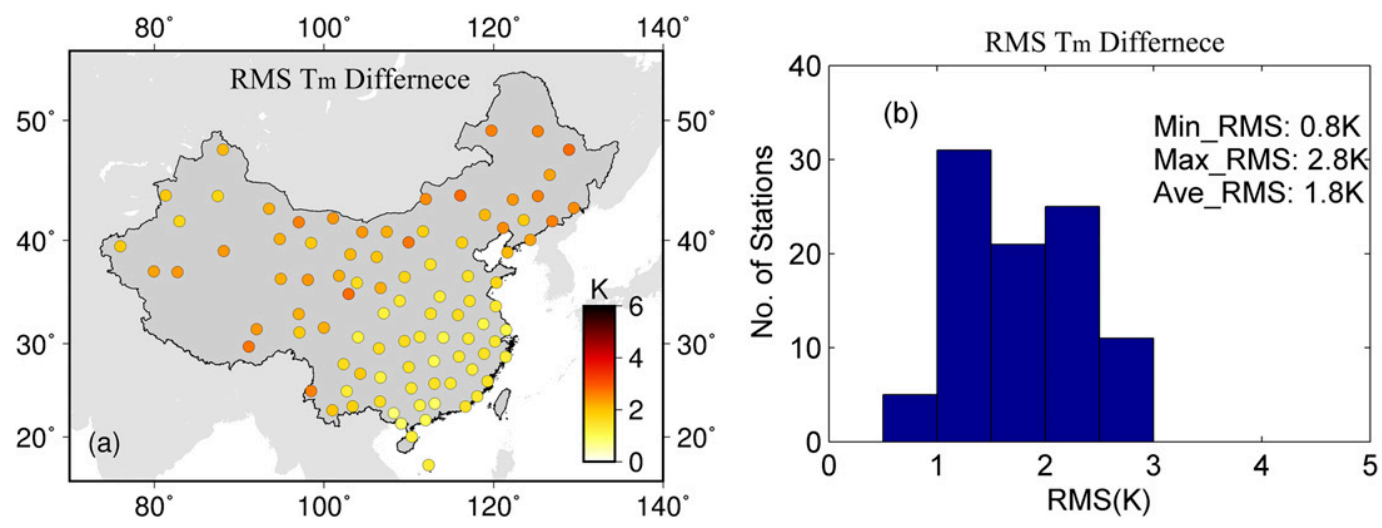

FIG. 5. (a) Geographic distribution of RMS of $T_{m}$ differences (K) (ERA-Interim minus radiosonde) and (b) histogram of $T_{m}$ difference RMS. 
TABLE 1. PW errors due to errors in ZTD, $T_{m}$, and $P_{s}$ as well as the total PW errors. Mean values are calculated based on time series of all GPS stations from 1999 to 2015.

\begin{tabular}{|c|c|c|c|c|c|c|c|}
\hline \multirow[b]{2}{*}{ Variable } & \multirow[b]{2}{*}{ Mean } & \multirow[b]{2}{*}{ Min error } & \multirow[b]{2}{*}{ Max error } & \multirow[b]{2}{*}{ Mean error } & \multicolumn{3}{|c|}{ PW error $(\mathrm{mm})$} \\
\hline & & & & & Min & $\operatorname{Max}$ & Mean \\
\hline PW (mm) & 17.8 & - & - & - & - & - & - \\
\hline ZTD (mm) & 2318.1 & 2.7 & 4.6 & 3.9 & 0.42 & 0.71 & 0.60 \\
\hline Constant & 2.2779 & - & - & 0.0024 & 0.33 & 0.33 & 0.33 \\
\hline$P_{s}(\mathrm{hPa})$ & 887.9 & 0.1 & 2.1 & 0.7 & 0.04 & 0.74 & 0.25 \\
\hline$T_{m}(\mathrm{~K})$ & 273.3 & 0.8 & 2.8 & 1.8 & - & - & - \\
\hline$k_{2}^{\prime}\left(\mathrm{KhPa}^{-1}\right)$ & 17 & - & - & 10 & - & - & - \\
\hline$k_{3}\left(10^{5} \mathrm{~K}^{2} \mathrm{hPa}^{-1}\right)$ & 3.776 & - & - & 0.004 & - & - & - \\
\hline$Q$ & 6.455 & 0.05 & 0.080 & 0.063 & 0.14 & 0.22 & 0.17 \\
\hline Total PW error (mm) & - & - & - & - & 0.55 & 1.10 & 0.75 \\
\hline
\end{tabular}

$$
\sigma_{Q}=10^{-6} \rho_{w} R_{v} \sqrt{\left(\frac{\sigma_{k_{3}}}{T_{m}}\right)^{2}+\sigma_{k_{2}^{\prime}}^{2}+\left(k_{3} \frac{\sigma_{T_{m}}}{T_{m}^{2}}\right)^{2}},
$$

where $\sigma_{k_{3}}, \sigma_{k_{2}^{\prime}}$ and $\sigma_{T_{m}}$ denote the uncertainty of $k_{3}, k_{2}^{\prime}$, and $T_{m}$, respectively.

Based on the statistical values of each variable discussed above, the PW errors associated with errors in $\mathrm{ZTD}, P_{s}$, and $T_{m}$ as well as the total PW errors for all GPS stations are summarized in Table 1. The 3.9-mm uncertainty for ZTD is used according to results in section 3a. Minimum, maximum, and mean errors of $0.1,2.1$, and $0.7 \mathrm{hPa}$ are used for $P_{s}$ and $0.8,2.8$, and $1.8 \mathrm{~K}$ are used for $T_{m}$ based on the analysis in sections $2 \mathrm{~d}$ and $3 \mathrm{~b}$. The mean total PW error is approximately $0.75 \mathrm{~mm}$, with minimum and maximum errors of 0.55 and $1.10 \mathrm{~mm}$, respectively. This PW accuracy is in the same range as found in previous studies (Wang et al. 2007; Vey et al. 2009).

\section{Comparison of radiosonde and GPS}

\section{a. Radiosonde type change identification}

As stated in Wang and Zhang (2008), there is only limited information on radiosonde types available in the IGRA metadata (available online at ftp://ftp.ncdc. noaa.gov/pub/data/igra/). As in their study, we obtain as much radiosonde type information as is available from the WMO report titled "WMO catalogue of radiosondes and upper-air wind systems" updated in 2001, July 2007, and July 2014 (WMO 2014). If two consecutive versions show different types for a radiosonde station, then type changes must have occurred between the dates of the two versions of the document. Other resources on the radiosonde type identification in China are available from previous studies, including Wang and Zhang (2008), Liang et al. (2012), Zhao et al. (2012), and Sun et al. (2013), and are listed in appendix A.
For remaining type changes described in the WMO reports that occurred at an unknown time, we examine visually the time series of monthly mean PW differences (radiosonde minus GPS) (monthly mean values of individual PW differences) to identify the specific change date (i.e., year and month). Note that this method depends on the reliability of PW from both radiosonde and GPS data.

Examples illustrating how radiosonde type changes are identified based on monthly mean PW differences are shown in Figs. 6 and 7. The four stations presented in Fig. 6 have known dates when the type changed and these changes were reported in several previous papers, namely, from GZZ2 to GTS1 at the beginning of 2002 for BJFS (54511) (Wang and Zhang 2008; Zhao et al. 2012), from GZZ2 to GTS1 in December 2005 for KMIN (56778) (Zhao et al. 2012), from GZZ2 to GTS1 in January 2005 for LHAS (55591) (Liang et al. 2012), and from GZZ2 to GTS1 in October 2006 for WUHN (57494) (Zhao et al. 2012). These known changes can be identified confidently from PW difference time series for all sites except LHAS as shown in Fig. 6. GPS site LHAZ is collocated with LHAS and has similar PW differences when compared to radiosonde station 55591 and therefore is not presented here. Differences before and after the type change for station LHAS are not very obvious, which might be because LHAS is located on Tibetan Plateau with quite low PW so any sensor error correlated with temperature or moisture may also be small and less obvious to detect. Dry biases in PW for GZZ2 radiosonde data on the Tibetan Plateau were discussed in Takagi et al. (2000) and Liu et al. (2005) and may produce uncertainties in the radiation budget for the Tibetan Plateau if not corrected (Liu et al. 2005). The PW difference time series for all four stations in Fig. 6 have results consistent with the previously mentioned studies (Wang and Zhang 2008; Liang et al. 2012; Zhao et al. 2012).

We are not able to provide information on radiosonde type changes outside the common observation period of 

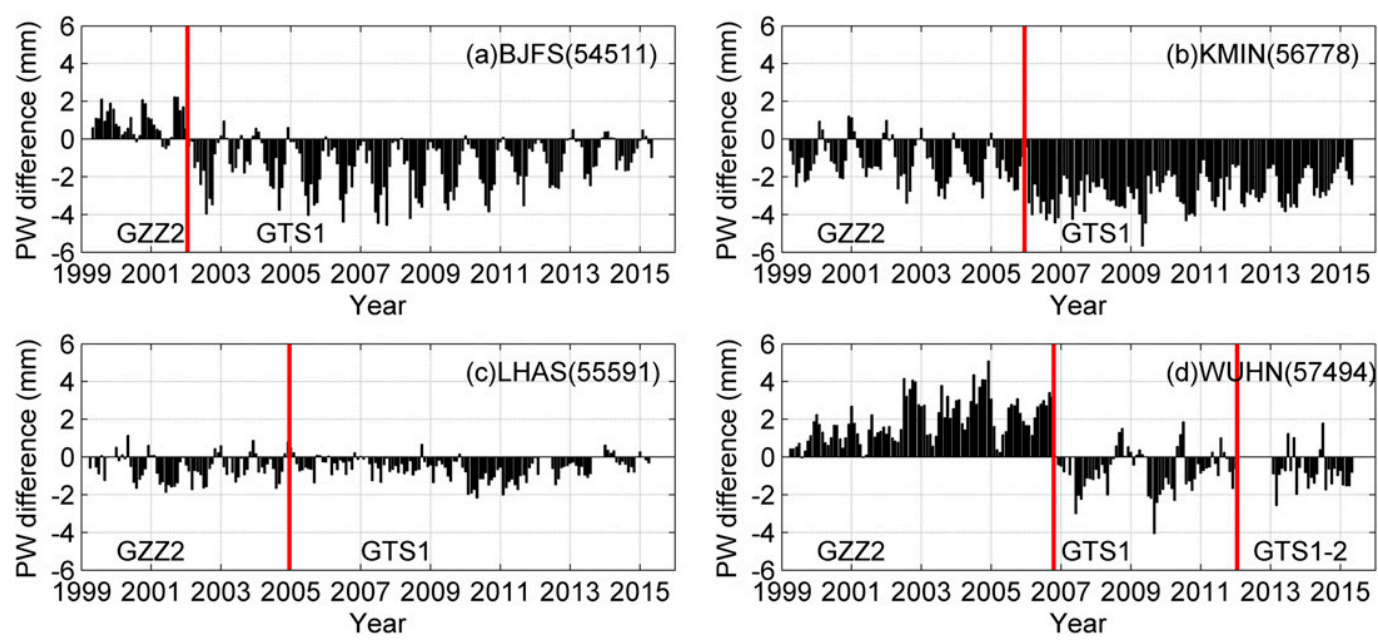

FIG. 6. Examples of monthly mean PW differences (radiosonde minus GPS) for four sites where the exact date of the change in radiosonde type was known. The vertical red lines denote the time when the radiosonde changed with the corresponding radiosonde type labeled. GPS station name and the matched radiosonde WMO identifier in parentheses are indicated at the top right in each panel.

radiosonde and GPS from 1999 to 2015 . Figure 7 presents PW differences for the rest of the matched GPS and radiosonde stations containing radiosonde type changes where the exact date of the radiosonde type change was not known prior to this study. Systematic errors in different radiosonde types are quite different, making it easy to visually identify the month of the type change for these stations, using a method similar to that of Wang and Zhang (2008). We report these changes in appendix A and assign the date of the change to the first day of the month. The uncertainty in the date of the change of \pm 0.5 months is not large enough to impact the statistical estimate of PW trends. Almost all stations equipped with type GZZ2 show wet biases in PW. The wet biases in goldbeater's skin humidity sensors in the GZZ2 radiosondes were also found in Wang and Zhang (2008). However, the dry biases in GTS1 equipped with the carbon hygristor sensor as shown in Fig. 7 are contrary to the conclusions in Wang and Zhang (2008), where wet biases for the carbon hygristors in VIZ and RS SDC radiosondes were generally found. There are apparently different systematic errors existing in the same type of humidity sensor technology coming from different manufacturers. Dry biases in GTS1 were also revealed in comparisons between GTS1 and Vaisala RS92 in Li (2010) and in comparisons between radiosonde and radio occultation profiles from the Constellation Observing System for Meteorology, Ionosphere, and Climate (COSMIC) (Ho et al. 2010). Stations XIAM (59134) and YONG (59981) stand out with significantly different characteristics for GTS1 statistics, where little or no annual signal can be found in the PW difference time series. These sites are both coastal stations at relatively low latitudes $\left(24.450^{\circ}\right.$ and $16.834^{\circ} \mathrm{N}$, respectively). Generally, the newly deployed GTS1-1 and GTS1-2 perform better than the older types as shown in Fig. 7. Biases are generally dry for GTS1-1 and wet for GTS1-2, but very small. Station YONG (59981) has a significant change in characteristics in 2014, which is after the date of the last report documenting type changes. Based on this work, we suggest that a type change from GTS1 to one of the later models is likely to have occurred at this date. It is not listed in appendix A as a type change that needs further investigation. Aside from station YONG, there is no evidence of any additional unreported type changes of statistical significance prior to the last report in 2014. The visual identification of known type changes with unknown date is facilitated for time series that include at least one annual cycle following the change. Therefore any other type changes after the last version published in July 2014 cannot be unambiguously identified without a longer time series. There is low probability for a change of equipment for stations already equipped with the latest generation of radiosonde (GTS1-1 and GTS1-2), but the time series for stations equipped with GTS1 merit continued monitoring in the future. Potential errors after 2014 due to unidentified type changes for GTS1 will not significantly contaminate the statistical results for trend estimation due to the relatively short period from July 2014 to April 2015. While it would be beneficial to identify the exact date of type changes, it is necessary to use monthly mean PW differences to reduce random errors so that the changes are detectable. Since climatological products are usually reported as monthly mean values, this approach satisfies its primary objective. 

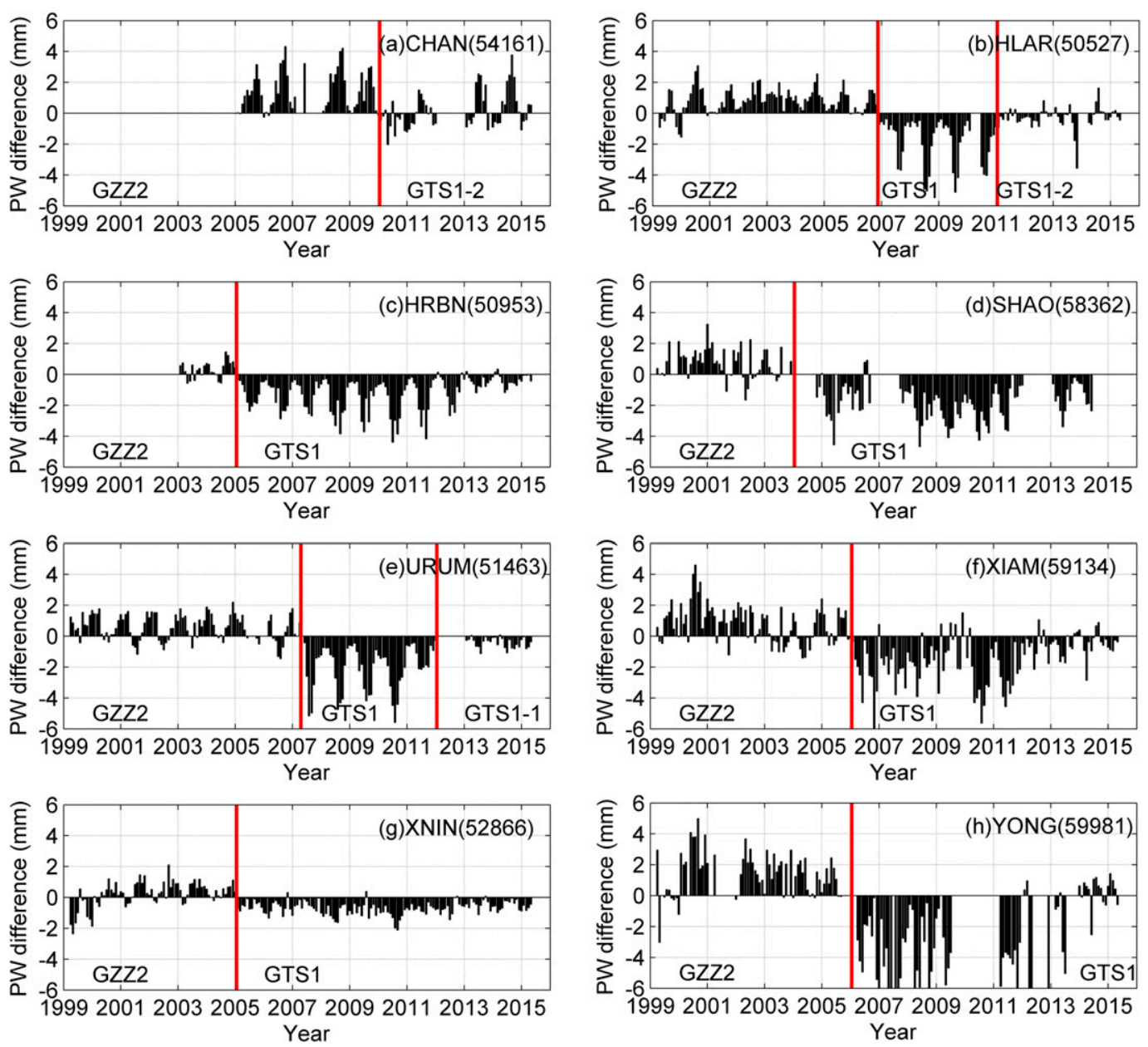

FIG. 7. As in Fig. 6, but for eight stations where the exact date of the change in radiosonde type was not known prior to this study.

The list of radiosonde stations with type changes detected by this PW comparison with nearby GPS stations and the related descriptions are given in Table A1 in appendix A.

\section{b. PW comparison}

Mean values and STDs of PW differences for all matched stations are grouped by the radiosonde type and are shown in Fig. 8a at 0000 and 1200 UTC combined, Fig. 8b at 0000 UTC only (0800 solar local time in Beijing) and Fig. 8c at 1200 UTC only (2000 solar local time in Beijing). Stations are plotted in order of increasing PW on the $x$ axis. In Fig. 8a, for GZZ2, all but three stations show wet biases, with a few as large as $2 \mathrm{~mm}$. The three stations with dry biases, KMIN (56778), LHAS (55591), and LHAZ (55591), all have elevation higher than $2000 \mathrm{~m}(2020,3660$, and $3660 \mathrm{~m}$, respectively). The other GZZ2 stations are all below $1000 \mathrm{~m}$ [except XNIN (52866) with elevation of $2408 \mathrm{~m}$ ], which indicates that there are generally wet biases for GZZ2 stations below $1000 \mathrm{~m}$ while generally dry biases for GZZ2 stations above $2000 \mathrm{~m}$. There is a larger moist bias at 0000 than at 1200 UTC for GZZ2, with mean PW differences of 1.0 and $0.2 \mathrm{~mm}$, respectively. This diurnal difference is significant for GZZ2 stations with high elevations. Whether this is a property of the sensor or not has not been determined.

For GTS1, almost all stations are found to have dry biases at both 0000 and 1200 UTC. Dry biases are slightly greater at 12 UTC compared to biases at 0000 UTC, with mean PW differences of -1.4 and $-0.9 \mathrm{~mm}$, respectively, and the mean of the station biases is $-1.2 \mathrm{~mm}$ for combined 0000 and 1200 UTC. The STD of the PW differences increases with increasing mean PW level (Fig. 8) at all times. This is due to increased variability of moisture under high moisture conditions, where the in situ radiosonde sensor may sample local atmospheric conditions that are different from the mean 
(a) PW difference (Radiosonde minus GPS) at 00\&12 UTC

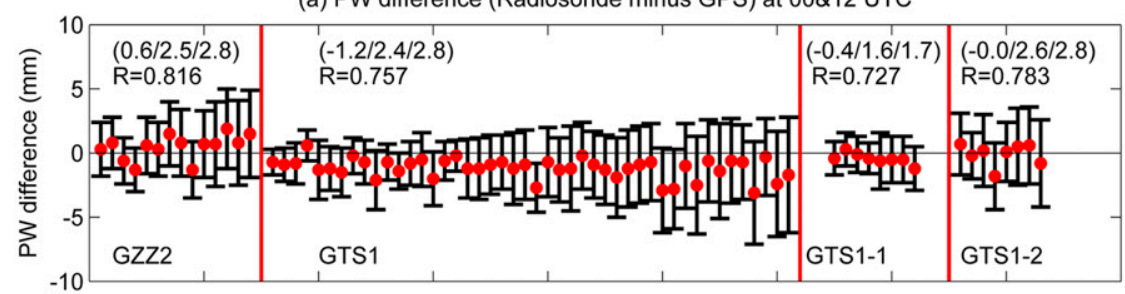

(b) PW difference (Radiosonde minus GPS) at 00 UTC

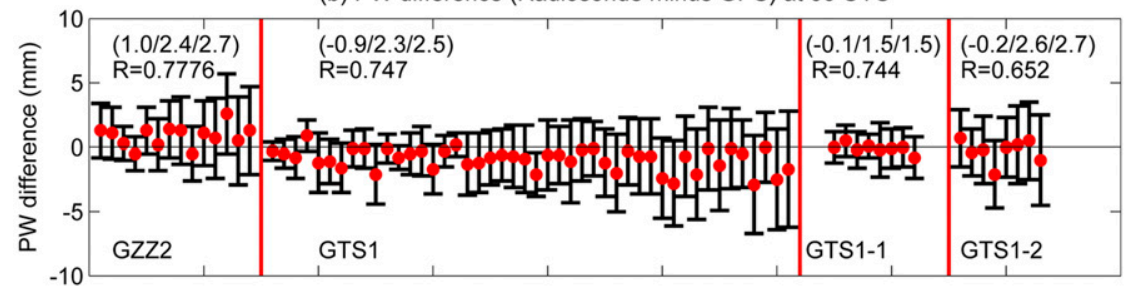

(c) PW difference (Radiosonde minus GPS) at 12 UTC

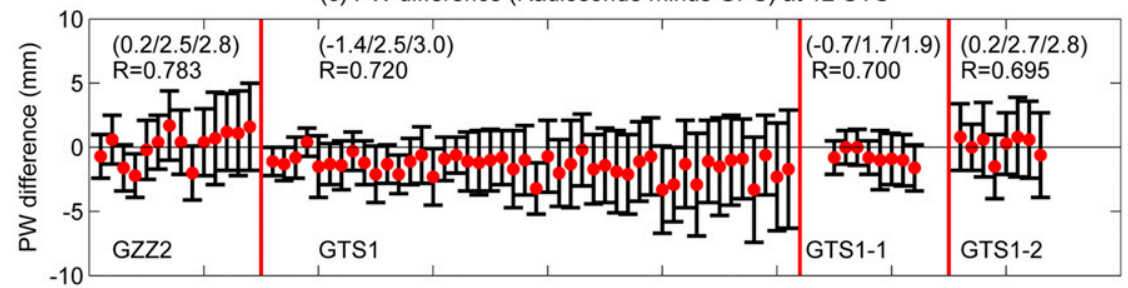

FIG. 8. Mean values (red dots) and STD (vertical black error bars) of PW differences (radiosonde minus GPS) at all matched stations in China for four radiosonde types at (a) 0000 and 1200, (b) 0000, and (c) 1200 UTC. Mean value, STD, and RMS of differences $(\mathrm{mm})$ and correlation coefficients of monthly PW anomalies are given for each type across the top in each panel. Stations are ordered by increasing average annual GPS PW on the $x$ axis.

conditions sampled by the azimuthally averaged GPS raypaths extending down to $10^{\circ}$ elevation angle. This also shows up in the correlation for the STD of the radiosonde minus GPS PW difference with latitude (Fig. 9), with lower-latitude sites generally having higher moisture and higher moisture variability.

For the newly deployed GTS1-1, which is equipped with a carbon hygristor sensor similar to GTS1, the performance is better than GTS1 but there are still slight dry biases of approximately $0.4 \mathrm{~mm}$ in $\mathrm{PW}$ compared to GPS results, and 1200 UTC has a larger bias than 0000 UTC, with dry biases of 0.1 and $0.7 \mathrm{~mm}$, respectively. On the other hand, there are slight wet biases of approximately $0.3 \mathrm{~mm}$ for GTS1-2 stations, with biases of approximately $0.1 \mathrm{~mm}$ at 0000 UTC and approximately $0.5 \mathrm{~mm}$ at 1200 UTC. As shown in Fig. 8, GTS1-1 shows the best agreement with GPS PW with STD of about $1.7 \mathrm{~mm}$, while GTS1-2 has the largest STD of about $2.7 \mathrm{~mm}$ but the smallest systematic bias. Statistics for PW differences for each matched GPS and IGRA station are listed in Table S1 in the supplemental material.
The correlation coefficients between GPS and radiosonde monthly PW anomalies are also indicated in Fig. 8. The monthly PW anomaly is calculated as the deviation of the monthly PW from the monthly PW climatology (mean value of monthly PW over the whole period from 1999 to 2015). The correlation

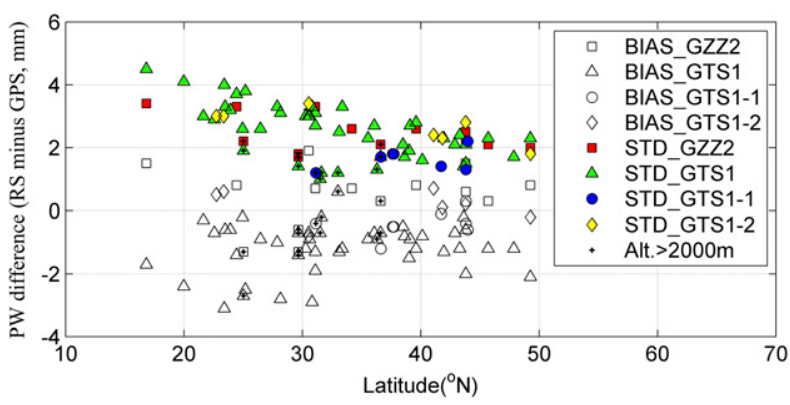

FIG. 9. Mean values (open symbols) and STD (color-filled symbols) of PW differences (radiosonde minus GPS) for four radiosonde types as a function of station latitude. There is a strong correlation for STD because of the increased variability of PW at lower latitudes, especially when stations with altitude $>2000 \mathrm{~m}$ (plus symbols) are excluded. 

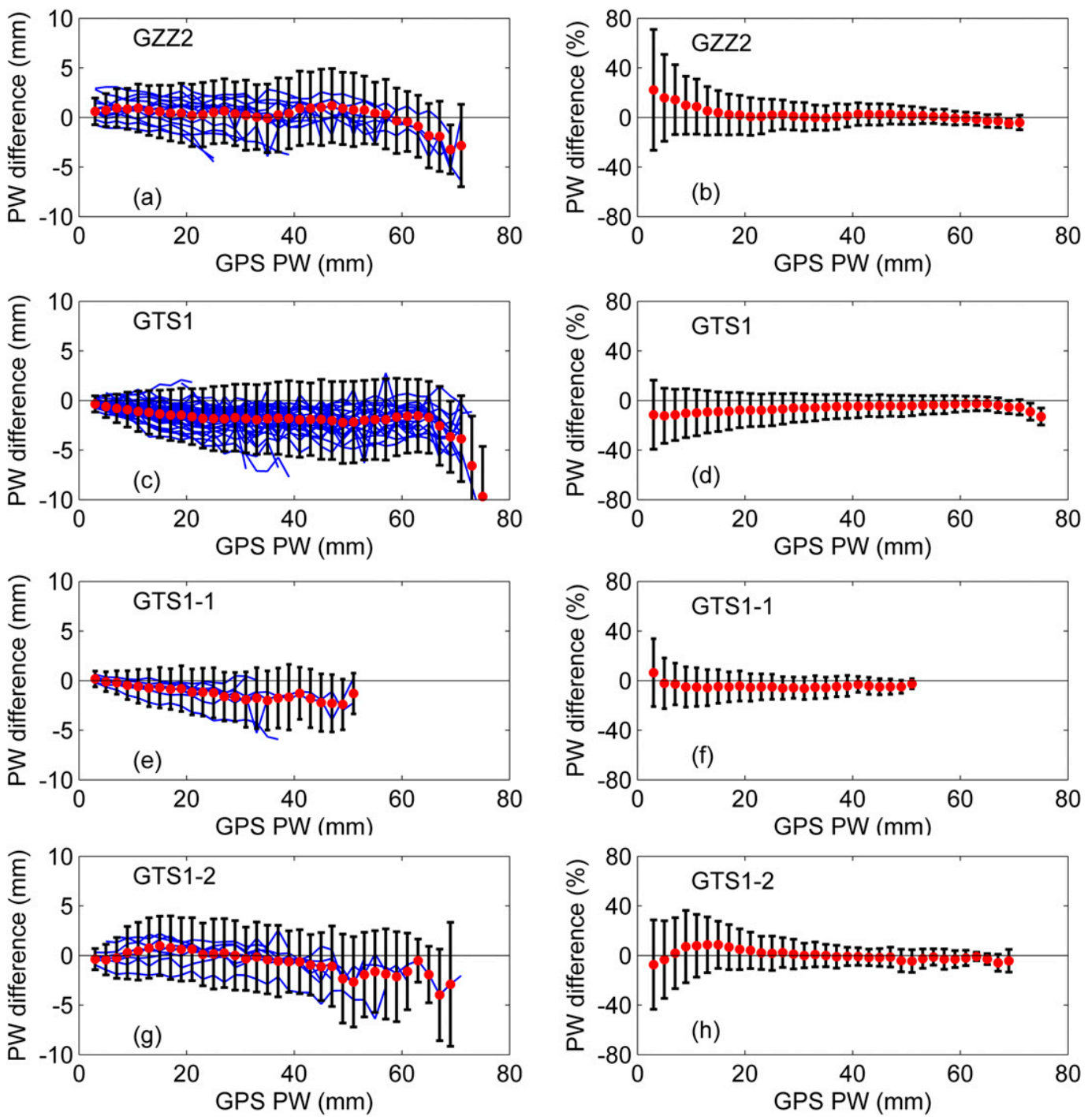

FIG. 10. Variations of (left) absolute and (right) relative PW differences (radiosonde minus GPS) with PW from GPS for (top)-(bottom) four types of radiosonde. Red dots denote the mean value with STD represented by vertical black error bars. Blue lines show the mean PW differences for individual sites.

coefficients of monthly PW anomalies are around 0.70.8 for all types.

Variations of absolute and relative PW differences as a function of GPS PW with an interval of $2 \mathrm{~mm}$ are presented in Fig. 10. The relative PW differences are calculated as the absolute PW differences (radiosonde minus GPS) divided by GPS PW in percentage. Blue lines indicate the absolute PW difference for individual stations. The moist biases for PW smaller than $55 \mathrm{~mm}$ can be observed for GZZ2. There are dry biases at PW larger than $60 \mathrm{~mm}$. However, these biases are dominated by the effects at only three sites. Three sites on the Tibetan Plateau behave quite differently and have dry biases over the entire sampled range of PW. The relative differences are not significant for PW from 15 to $72 \mathrm{~mm}$. For GTS1, in the PW range of 0-20 mm, the dry bias and STD increase with increasing PW and then stay roughly stable at approximately $-2-\mathrm{mm}$ mean and about 3 STD over the range of PW from 20 to $65 \mathrm{~mm}$. A few sites with PW $(>70 \mathrm{~mm})$ produce exceptionally large negative biases, which is also clear in the relative differences, reaching approximately $10 \%-15 \%$ for large PW. Dry biases are clearly shown for GTS1 over the whole PW range. Biases are similar for GTS1-1 up to $50 \mathrm{~mm}$ of PW, and show better performance at small PW $(<10 \mathrm{~mm})$. However, there are no data for very high PW sites for GTS1-1, and therefore there is no information on the performance of GTS1-1 in that range. There are 
significant dry biases for GTS1-2 for PW $>45 \mathrm{~mm}$, but once again there are only two sites where PW is high enough to show this feature.

\section{c. PW trend comparison}

As mentioned in the introduction, changes in sensors within the radiosonde data record can induce large biases in the long-term humidity trend. In this section, the PW trend will be estimated and compared from both GPS and radiosonde data for matched stations over the period from 1999 to 2015.

The 5-point moving-average method is applied to the monthly PW anomaly time series, and the PW trends are then estimated using Sen's nonparametric method (Sen 1968) as

$$
\text { trend }=\operatorname{median}\left(\frac{x_{j}-x_{i}}{j-i}\right),
$$

where $x_{j}$ and $x_{i}$ are the monthly PW anomaly values at time $j$ and $i(j>i)$, respectively. This method provides a more robust slope estimate than the least squares method since it is insensitive to outliers or extreme values (Fan and Yao 2003), particularly for relatively small datasets, and it can also reduce the impacts of autocorrelation in time series. The statistical significance of the trends is tested using the Mann-Kendall tau method (Mann 1945; Kendall 1975) with 95\% confidence level. The MannKendall statistic $S$ is estimated as

$$
S=\sum_{i-1}^{n-1} \sum_{j=i+1}^{n}\left[\operatorname{sign}\left(x_{j}-x_{i}\right)\right]
$$

where $n$ denotes the number of data points.

The variance of $S$, denoted as $V(S)$, can be calculated as

$$
V(S)=\frac{n(n-1)(2 n+5)-\sum_{k=1}^{m} t_{k}\left(t_{k}-1\right)\left(2 t_{k}+5\right)}{18},
$$

where $m$ is the number of tied groups (a tied group is a set of data with the same value) in the time series and $t_{k}$ is the number of members of group $k$. When $n>10$, the standard normal test statistic $Z_{s}$ is then estimated as

$$
Z_{s}=\left\{\begin{array}{lll}
\frac{S-1}{\sqrt{V(S)}}, & \text { if } & S>0 \\
0, & \text { if } & S=0 \\
\frac{S+1}{\sqrt{V(S)}}, & \text { if } & S<0
\end{array}\right.
$$

At the $95 \%$ confidence level, the null hypothesis of no trend is rejected when $\left|Z_{s}\right|>1.96$.
Monthly PW anomaly time series and the corresponding trends for three pairs of GPS-radiosonde matched stations are presented in Fig. 11 and trends for all matched stations and the differences are summarized in Table 2. The significance at the $95 \%$ confidence level based on the above test is also reported in Table 2. Only matched stations with PW time series longer than $9 \mathrm{yr}$ in both GPS and radiosonde results are used in the trend analysis and comparison.

For BJFS (54511), trends estimated from radiosonde PW are -0.049 and $-0.037 \mathrm{~mm} \mathrm{yr}^{-1}$ at 0000 and 1200 UTC, respectively, while trends are in opposite sign from GPS PW, 0.023 and $0.060 \mathrm{~mm} \mathrm{yr}^{-1}$ at 0000 and 1200 UTC, respectively. Similar conclusions can be drawn for KMIN (56778) and WUHN (57494), namely upward trends are found from GPS PW but radiosonde PW show downward trends for the period from 1999 to 2015. In addition, the monthly PW anomaly from radiosonde data agree better with GPS data in recent years (after 2011) than before 2003, especially for BJFS (54511) and KMIN (56778).

From Table 2 we can find that almost all stations show downward PW trends during the period from 1999 to 2015 based on radiosonde data except XIAA (57036) at 0000 UTC, which is not statistically significant. However, trends from GPS PW in Table 2 that are statistically significant are almost all positive [except YONG (59981), which is located on an island in the southernmost part of China] and greater than radiosonde trends for all stations except for LHAS (55591), which is again not statistically significant. The reason for the reversal in the PW trend estimates between GPS and radiosonde is primarily because GZZ2 was widely used before 2006 and contained wet biases as discussed above, whereas the newly used GTS1 shows significant dry biases in PW, which introduces significant negative biases in the trend estimates.

The positive PW trends from GPS are more consistent with the expected global change in moisture due to rising temperatures (Trenberth et al. 2003). However, the trends in Table 2 are smaller than the about $7 \%$ change predicted by the Clausius-Claperyron equation assuming constant relative humidity (e.g., Soden et al. 2002) and approximately $0.6-\mathrm{K}$ surface temperature change over 30 years (e.g., Santer et al. 2006). These regionally varying trend results will inform future research efforts to understand regional variations in moisture and precipitation trends.

The difference between trends estimated from uncorrected and corrected radiosonde records has been observed previously in Zhao et al. (2012), where it was also stated that these uncorrected radiosonde records were assimilated into the global reanalyses. Large 
(a)BJFS(54511) at 00 UTC

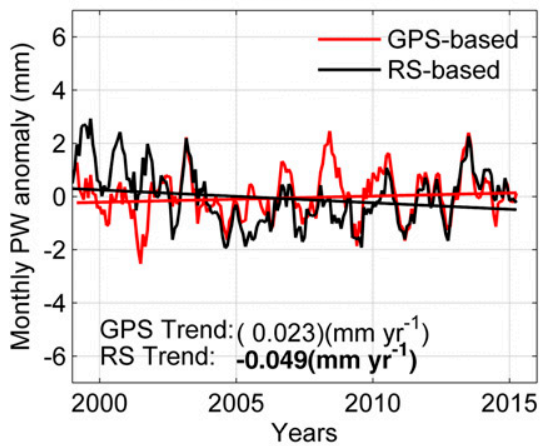

(c) KMIN(56778) at 00 UTC

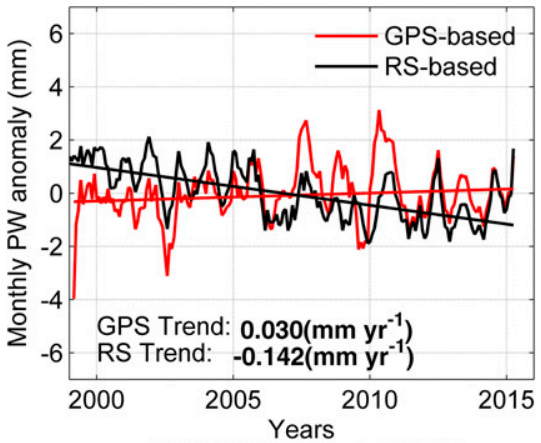

(e)WUHN(57494) at 00 UTC

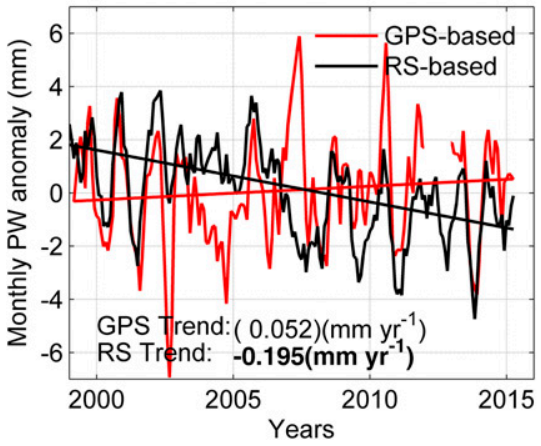

(b)BJFS(54511) at 12 UTC

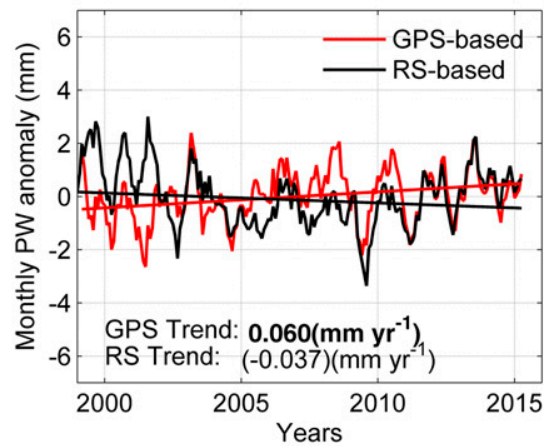

(d) KMIN(56778) at 12 UTC

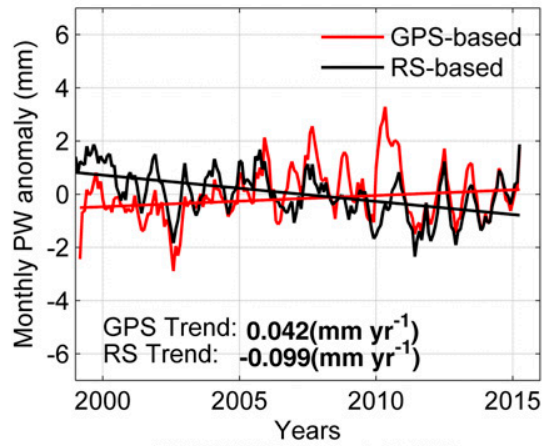

(f)WUHN(57494) at 12 UTC

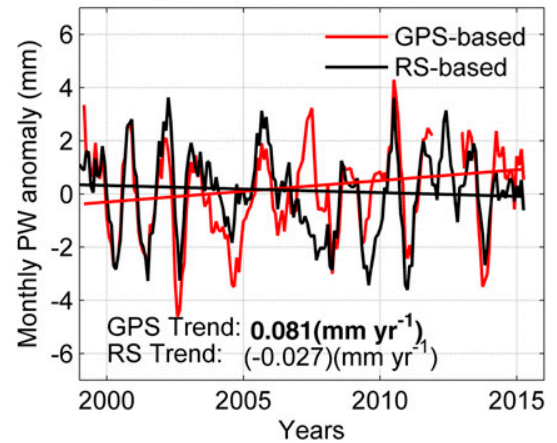

FIG. 11. The 5-point moving-average monthly PW anomaly time series from GPS (red line) and radiosonde data (black line) and the corresponding trend estimates (straight lines) for three pairs of matched GPS-radiosonde stations at (a),(c),(e) 0000 and (b),(d),(f) 1200 UTC. Trends are annotated at the bottom in each panel where numbers in boldface denote statistically significant estimates; numbers in parentheses indicate no statistical significance.

differences were shown between reanalysis trends and corrected radiosonde trends that have not been confirmed with any other moisture data source. These results provide further evidence that illustrate the improved trends and expand the dataset to a broader region of the country, spanning more climate zones and including areas not sampled by radiosondes. The time series from GPS PW that are made available in this study show shorter-term trends that are consistent in sign to the mapped longer-term values in Zhao et al. (2012), indicating that GPS PW are becoming a valuable source of observations. As the time series increase in length, they can confirm and improve trends in reanalysis products that are independent of radiosonde observational errors, and over the last four years the dataset has proven to be useful for verifying the accuracy of regional spatial moisture variations in the reanalysis.

\section{Comparison of ERA-Interim and GPS}

The ERA-Interim reanalysis is one of the leading reanalysis products for interpreting changes in climate, and one important moisture dataset included in the 
TABLE 2. PW trend estimates $\left(\mathrm{mm} \mathrm{yr}^{-1}\right)$ from GPS and radiosonde data at 0000 and 1200 UTC and the differences (radiosonde minus GPS). Numbers for trend estimates in boldface denote statistical significance with confidence level of $95 \%$; numbers in parentheses are not statistically significant.

\begin{tabular}{|c|c|c|c|c|c|c|c|}
\hline \multirow[b]{2}{*}{ GPS (IGRA) station } & \multirow[b]{2}{*}{ Station elev (m) } & \multicolumn{3}{|c|}{0000 UTC $\left(\mathrm{mm} \mathrm{yr}^{-1}\right)$} & \multicolumn{3}{|c|}{1200 UTC $\left(\mathrm{mm} \mathrm{yr}^{-1}\right)$} \\
\hline & & GPS & Radiosonde & Difference & GPS & Radiosonde & Difference \\
\hline BJFS (54511) & 98.4 & $(0.023)$ & -0.049 & -0.072 & 0.060 & $(-0.037)$ & -0.097 \\
\hline CHAN (54161) & 258.7 & $(0.016)$ & -0.078 & -0.094 & 0.052 & -0.032 & -0.084 \\
\hline HLAR (50527) & 633.5 & $(-0.002)$ & -0.126 & -0.124 & 0.022 & $-\mathbf{0 . 0 7 2}$ & -0.094 \\
\hline HRBN (50953) & 184.5 & $(0.020)$ & $-\mathbf{0 . 1 0 2}$ & -0.122 & 0.045 & -0.086 & -0.131 \\
\hline KMIN (56778) & 2019.1 & 0.030 & -0.142 & -0.172 & 0.042 & -0.099 & -0.141 \\
\hline LHAS (55591) & 3659.3 & $(-0.006)$ & $-\mathbf{0 . 0 3 2}$ & -0.026 & $(-0.013)$ & $(-0.002)$ & 0.011 \\
\hline LHAZ (55591) & 3659.3 & $(-0.006)$ & $-\mathbf{0 . 0 3 2}$ & -0.026 & $(0.019)$ & $(-0.002)$ & -0.021 \\
\hline SHAO (58362) & 11.8 & $(0.050)$ & -0.097 & -0.147 & 0.070 & -0.130 & -0.200 \\
\hline URUM (51463) & 919.1 & 0.029 & -0.147 & -0.176 & 0.056 & -0.080 & -0.136 \\
\hline WUHN (57494) & 40.3 & $(0.052)$ & -0.195 & -0.247 & 0.081 & $(-0.027)$ & -0.108 \\
\hline XIAA (57036) & 543.6 & $(-0.020)$ & $(0.039)$ & -0.019 & $(0.015)$ & $(-0.003)$ & -0.018 \\
\hline XIAM (59134) & 96.0 & $(-0.015)$ & -0.206 & -0.191 & $(0.023)$ & -0.247 & -0.270 \\
\hline XNIN (52866) & 2407.7 & $(0.020)$ & -0.082 & -0.102 & $(0.020)$ & $-\mathbf{0 . 0 2 2}$ & -0.042 \\
\hline YONG (59981) & 7.4 & -0.120 & -0.460 & -0.340 & $(-0.045)$ & -0.481 & -0.436 \\
\hline
\end{tabular}

reanalysis over China is the radiosonde record. In this section, the PW time series derived from ERA-Interim reanalysis and GPS data will be compared, as well as the estimated PW trend over China during the period from 1999 to 2015.

\section{a. PW comparison}

Following the steps described in section 2c, PW values are retrieved at all GPS station locations from ERAInterim reanalysis products from 1 March 1999 to 30 April 2015 every 6h. Absolute differences (ERAInterim minus GPS) and relative differences are calculated for the common observations. The relative differences are defined as absolute differences divided by GPS $\mathrm{PW}$ in percentage. As shown from the geographic distribution of mean values of PW differences in Figs. 12a,b, the biases between ERA-Interim and GPS are smaller than $2 \mathrm{~mm}$ for almost all stations but relative differences are considerably smaller in southeastern China $(<20 \%)$ than western China $(\sim 20 \%-40 \%)$, primarily due to the very low values of $\mathrm{PW}$ over high-elevation regions of the Tibetan Plateau. The STDs of absolute differences shown in Fig. 12c for most stations are approximately $1.5-3 \mathrm{~mm}$. The highest standard deviations are found in regions with higher precipitation in southeastern China where moisture is more variable, and in the higher precipitation regions of northwestern China near Urumqi in Xinjiang Province, north of the Tian Shan, and within its mountain valleys. The correlation of higher STD where there is higher moisture and higher moisture variability has been observed in previous studies (e.g., Haase et al. 2003). For the relative differences, there are small STDs $(<15 \%)$ in southeastern China and relatively large STDs in western China $(>30 \%)$, once again due to the very low PW over the Tibetan Plateau and northern deserts.

The variations of mean values and STDs of relative PW differences in Fig. 13 show that the PW differences are strongly related to the altitude of stations. The mean relative difference for stations below $1000 \mathrm{~m}$ are within approximately $-10 \%$ and $10 \%$ but reach from $-20 \%$ to $50 \%$ for stations above $3000 \mathrm{~m}$. STDs are about $20 \%-$ $50 \%$ for high-elevation stations (above $2000 \mathrm{~m}$ ) and decrease to about $5 \%-30 \%$ for low-elevation stations (below $2000 \mathrm{~m}$ ).

Since there are strong seasonal signals in PW time series, the PW differences between ERA-Interim and GPS are also grouped into four seasons, namely spring [March-May (MAM)], summer [June-August (JJA)], fall [September-November (SON)], and winter [December-February (DJF)] (Fig. 14). The biases for ERA-Interim PW compared to GPS are very close to zero in all seasons. The STD of PW difference is largest in summer $(\sim 2.7 \mathrm{~mm}$ or $11.8 \%)$, and the mean value and RMS of PW differences are approximately $0.1(2.6 \%)$ and $2.9 \mathrm{~mm}(13.2 \%)$. On the other hand, the smallest absolute STD of PW differences are found in winter, namely $0.3(6.5 \%), 1.1(19.8 \%)$, and $1.3 \mathrm{~mm}(23.0 \%)$ for mean, STD, and RMS. PW differences are roughly equivalent in spring and fall, with mean differences of about $0.2 \mathrm{~mm}(4.3-5.4 \%)$, STD of about $1.9 \mathrm{~mm}(16.2-$ $19.5 \%)$, and RMS of about $2.0 \mathrm{~mm}(17.7 \%-21.2 \%)$. The error analysis in Table 1 shows that given GPS ZTD error estimates of $0.60 \mathrm{~mm}$ of delay and given the propagation of errors in pressure and temperature measurements, the "observational" error of GPS PW is approximately $0.75 \mathrm{~mm}$ of PW. This is close to the observed STD for winter values of ERA-Interim minus GPS, indicating the 

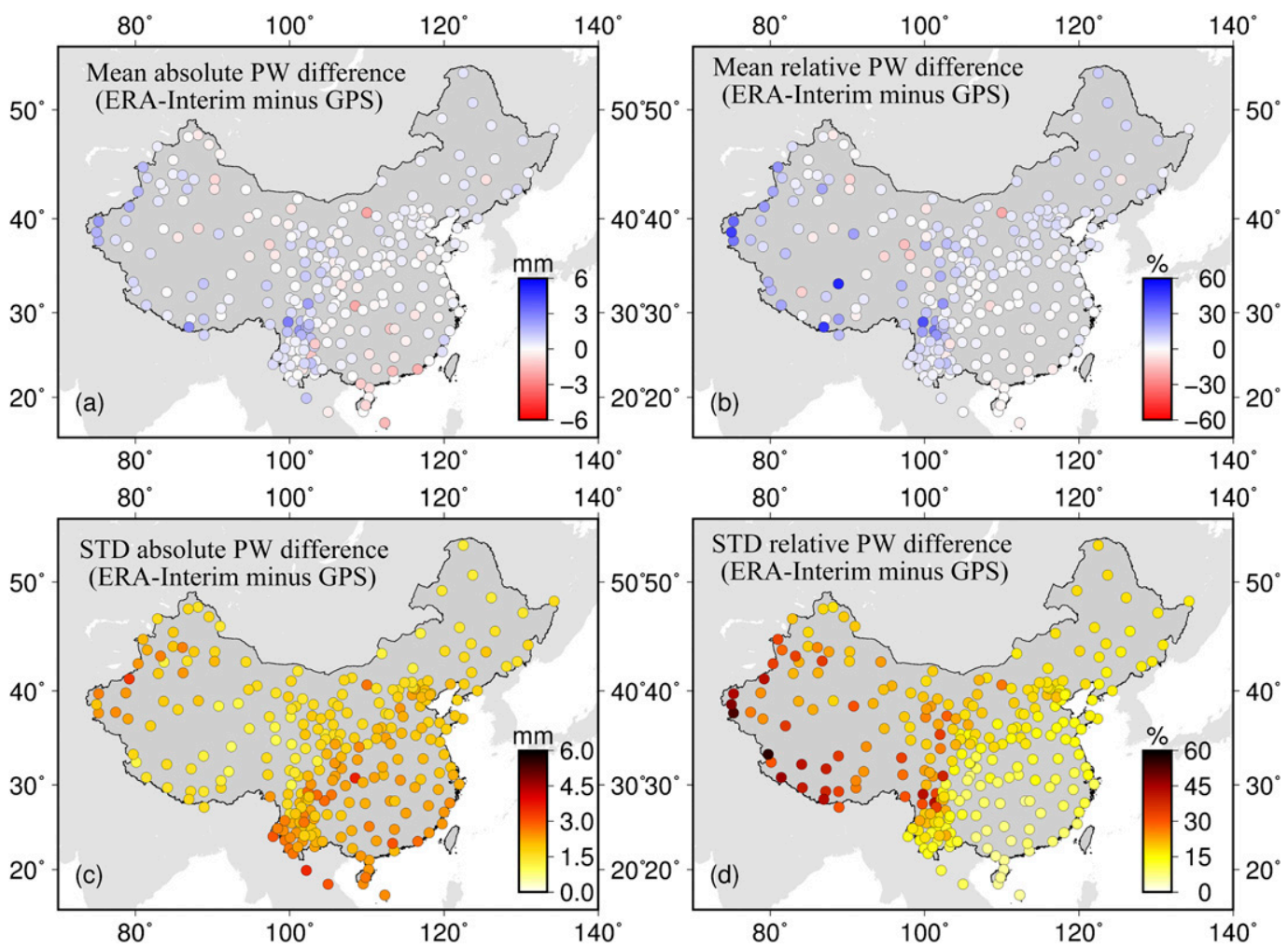

FIG. 12. Geographic distribution of (a),(b) mean values and (c),(d) STD of PW differences (ERA-Interim minus GPS), showing (a),(c) absolute differences $(\mathrm{mm})$ and (b),(d) relative differences (\%).

error estimates are reasonable and that the ERA-Interim is modeling the humidity well. However, the larger ERAInterim minus GPS STD in the summer of $2.7 \mathrm{~mm}$ PW, assuming the observational error is the same, indicates that there is significant model improvement that can be achieved, on the order of 3 times the observational error. This suggests that future data assimilation of the denser GPS PW observations over China could potentially have a significant impact on the accuracy of reanalyses and climate models, particularly in summer when moisture and precipitation are high.

The correlation coefficients between GPS and ERAInterim monthly PW anomalies are shown in Fig. 15. For most stations in China, the correlation coefficients are larger than 0.7. However, for stations on the Tibetan Plateau, the correlation coefficients are significantly smaller (below 0.4 for some stations), possibly due to the relatively low number of measurements in this region
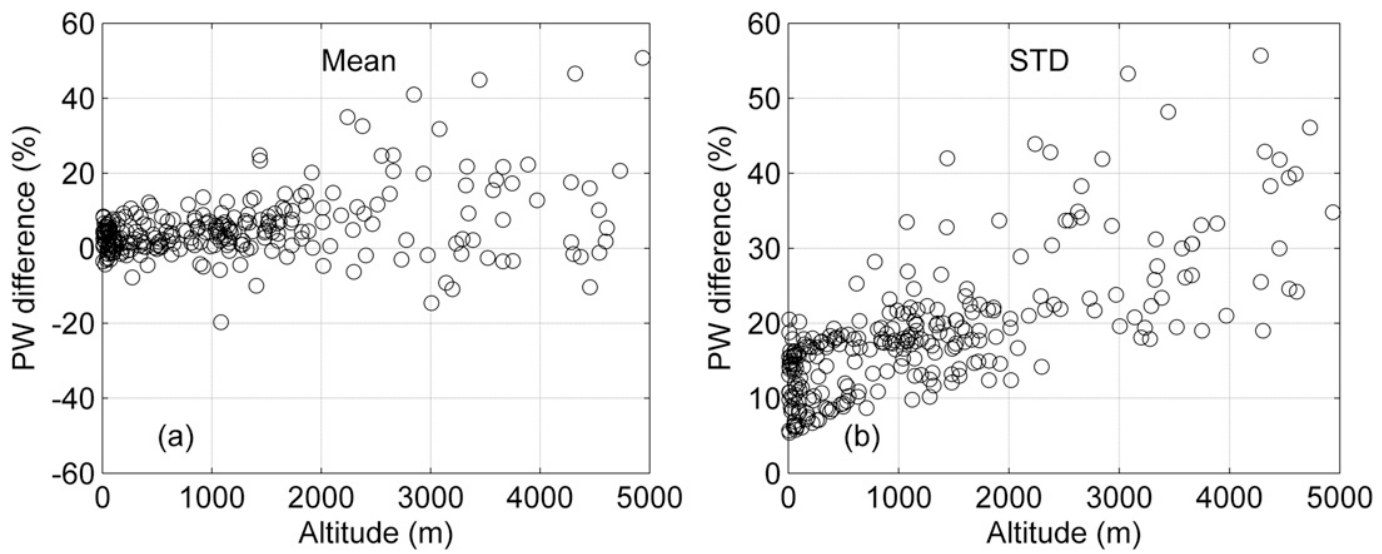

FIG. 13. Variations of (a) mean values and (b) STD of relative PW differences (ERA-Interim minus GPS) as a function of GPS station altitude. One circle denotes one GPS station. 

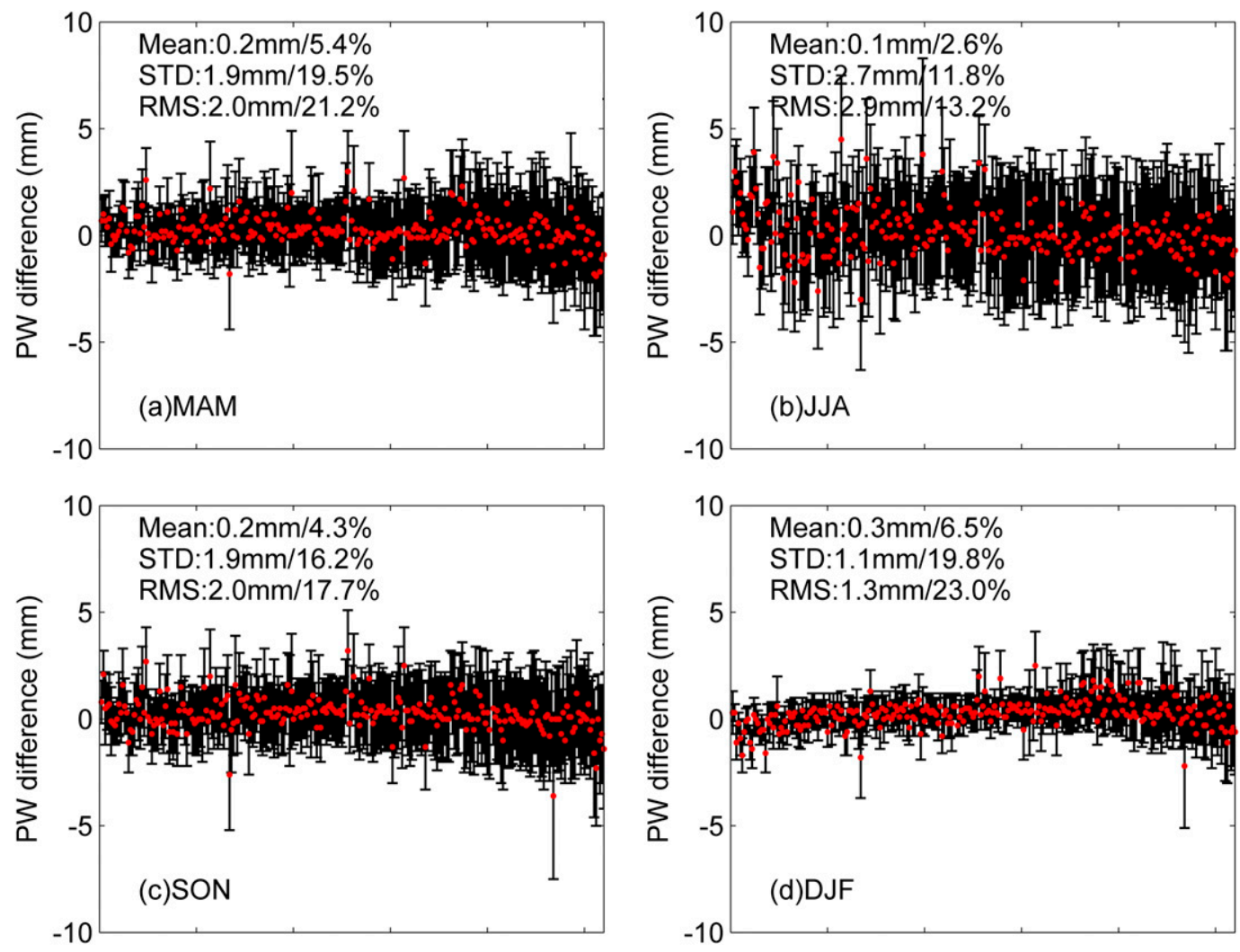

FIG. 14. Mean values (red dots) and STD (black vertical error bars) of relative PW differences (ERA-Interim minus GPS) at all GPS stations for four seasons: (a) MAM, (b) JJA, (c) SON, and (d) DJF. The average mean, STD, and RMS values and percentage are annotated at the top left in each panel. Stations are ordered by increasing average annual GPS PW on the $x$ axis.

which are assimilated in the reanalysis. We find the correlation coefficients generally decrease with increasing station altitudes, as shown in Fig. 15b.

\section{b. PW trend comparison}

Linear PW trends are derived based on ERA-Interim data following the method described in section $4 \mathrm{c}$ and compared to the GPS trends at 0000 and 1200 UTC for GPS stations with PW time series longer than $9 \mathrm{yr}$ (Fig. 16). The most obvious difference between PW trends from GPS and ERA-Interim is that almost all stations show downward ERA-Interim PW trends while both upward and downward trends are found from the GPS results. PW trends from ERA-Interim are similar

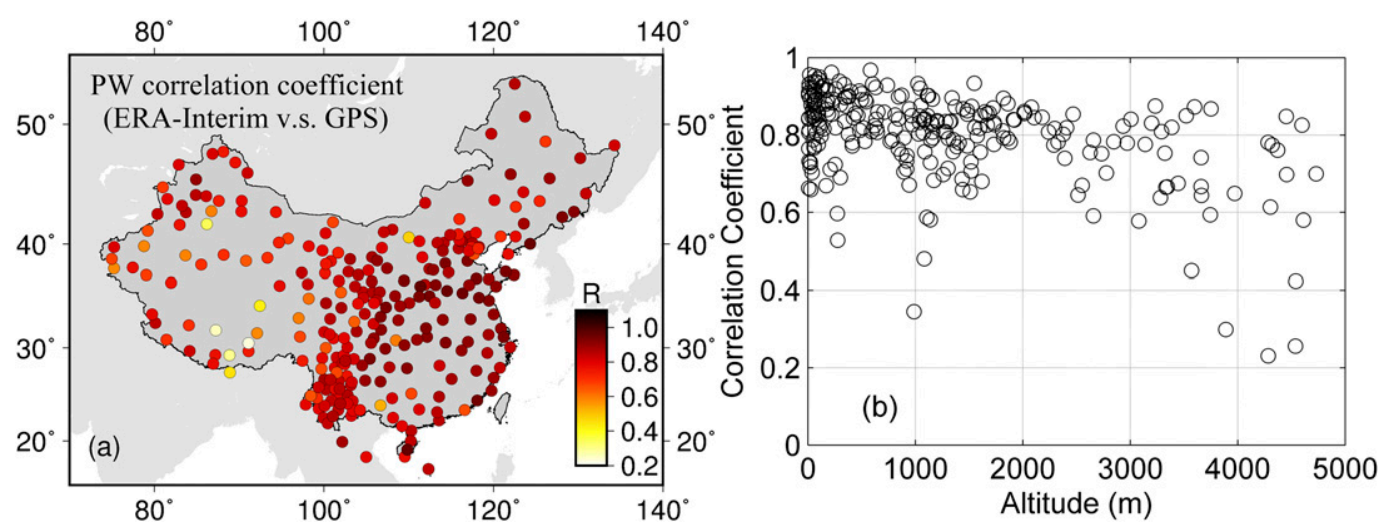

FIG. 15. (a) Geographical distribution of correlation coefficients between GPS and ERA-Interim monthly PW anomalies and (b) variations of correlation coefficients with station altitude. 

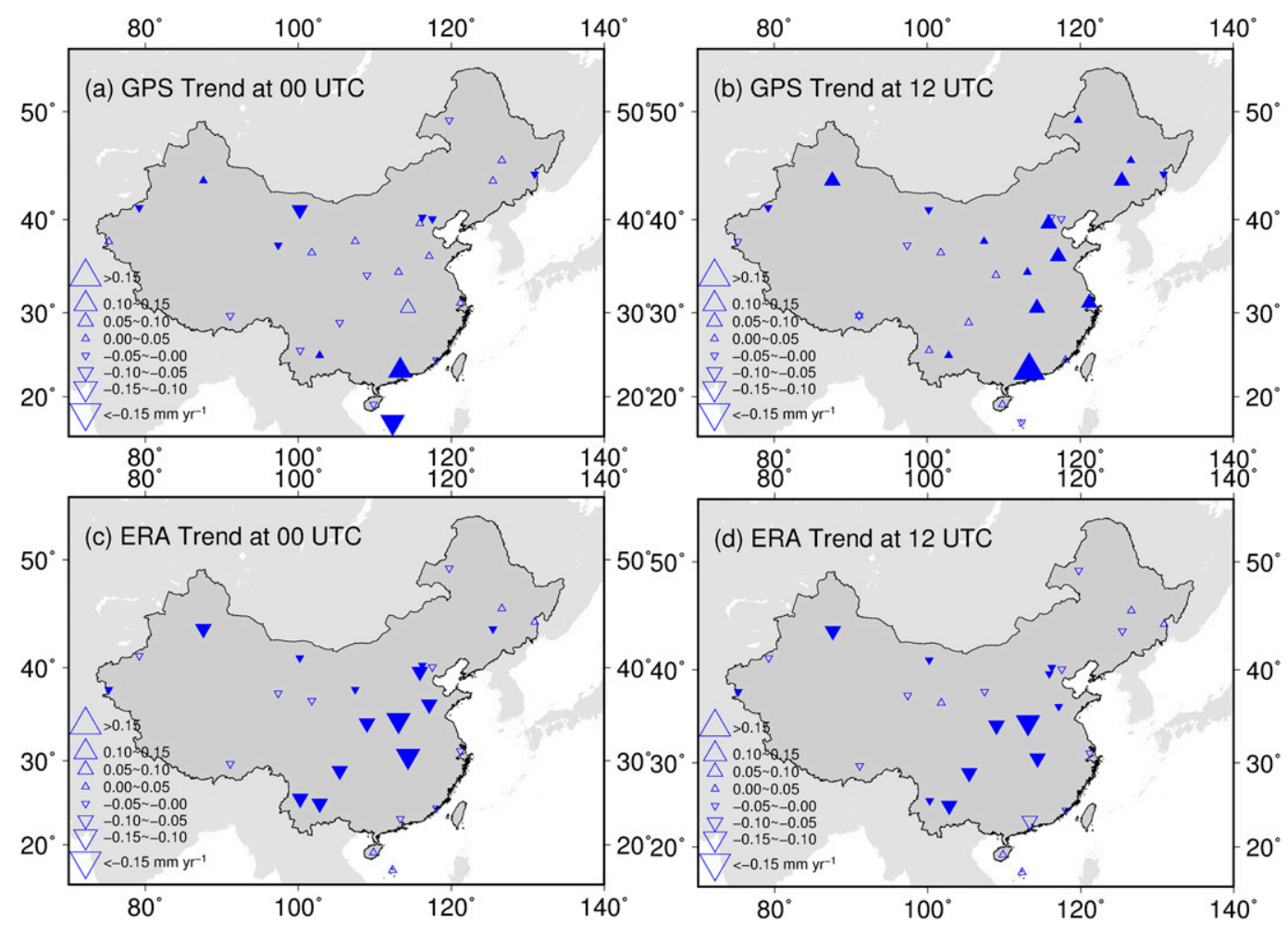

FIG. 16. Geographic distribution of PW trends $\left(\mathrm{mm} \mathrm{yr}^{-1}\right)$ at (a),(c) 0000 and (b),(d) 1200 UTC for all GPS stations with time series longer than $9 \mathrm{yr}$ for results derived from (a),(b) GPS and (c),(d) ERA-Interim. Blue-filled triangles denote statistical significance with $95 \%$ confidence level.

to results from radiosonde data because radiosonde data are an important input data source in the reanalysis data assimilation. For both GPS and ERA-Interim, the statistically significant PW linear trends at 0000 UTC are consistent with estimates at 1200 UTC. Trend estimates for all stations with PW time series longer than $9 \mathrm{yr}$ are presented in Table B1.

\section{Discussion}

This study goes significantly beyond previous studies of Chinese radiosonde errors due to instrumentation changes. By producing a consistently processed GPS PW dataset for the longest recorded set of GPS sites covering China, it was possible to detect and quantify the bias and dates associated with 10 additional instrumentation changes beyond the 5 originally quantified in the catalogs of Wang and Zhang (2008), Liang et al. (2012), and Zhao et al. (2012). It independently verifies changes detected based on dewpoint depression statistics (Dai et al. 2011). Table A1 serves as a comprehensive reference for the use of radiosonde records in China for climatological analysis, and brings attention to the potential for remaining humidity errors, even in the improved radiosonde dataset, for future studies that verify climate models against the historical record. The possibility of additional errors in reporting radiosonde types such as those detected by Dai et al. (2011) indicates that any correction algorithm should be used with care.

PW trends in China have been estimated for longer periods using corrected radiosonde data, for example over the period 1979-2012 in Zhao et al. (2015). However, the additional study of GPS PW trends at more than five stations presented here, although shorter, is important because there are no artificial discontinuities in the data that can call into question their accuracy. (The GPS PW data are made available online at http:// agsweb.ucsd.edu/gpspw_china as a resource to the community.)

Intercomparisons of climate models from phase 5 of the Climate Model Intercomparison Project (CMIP5) for the historical period have shown that there are large regional biases in precipitation, especially at higher quantiles [e.g., see Liu et al. (2014) for southern China]. GPS PW datasets such as this one provide regionally dense climatological time series of moisture variations in China among the dry high plateau climate in the northwest, continental climate in the northeast, and temperate climate with monsoonal influence in the 
southeast. These may help in the future to help diagnose diurnal and other biases in precipitation. Light rainfall is overestimated by a factor of 2 in global models (Stephens et al. 2010), the ratio of convective to stratiform precipitation is biased, and warm season precipitation tends to start too early in the day (Dai 2006). GPS PW is insensitive to clouds and rain and presents the best dataset for investigating diurnal variations in moisture over land. We have demonstrated this type of comparison for the ERA-Interim and shown that there are interesting differences, for example, where the correlation with ERAInterim is lower near the northwestern border region and in the elevated plateau. This illustrates the potential for the dataset to be used as a validation dataset for other climate models included in the CMIP5.

\section{Conclusions}

Ground-based GPS data measure atmospheric water vapor with low cost, in all weather conditions independently of the presence of clouds and precipitation, and with high temporal resolution and homogeneity over long time scales. As an independent data source, GPSderived water vapor information can be used to identify and quantify errors in radiosonde data and to verify numerical weather model reanalysis products. In this study, data from over 260 permanent GPS stations from the CMONOC network in China in the period from 1999 to 2015 were processed using the PPP method to solve for positions and ZTDs. To avoid any inconsistency among different reference frames, the reprocessed satellite orbit and clock products in the IGS08 reference frame were used over the entire period. Six GPS stations that also belong to the global IGS network were used to assess the accuracy of the derived position and zenith tropospheric delay solutions by comparing with IGS final products. The typical RMS position differences are approximately 5.7, 3.6, and $7.3 \mathrm{~mm}$ in the east, north, and upward component, respectively, which is in the same accuracy level as the IGS SINEX position solutions. Typical RMS ZTD differences for all stations are approximately $3.9 \mathrm{~mm}$, which is also comparable to IGS final ZTD products.

Water vapor weighted mean temperature $T_{m}$ and surface air pressure $P_{s}$ are two key parameters in the derivation of GPS PW from GPS ZTD. Values of $T_{m}$ are derived from the ERA-Interim, with an accuracy of approximately $1.8 \mathrm{~K}$ over China as assessed by comparing with radiosonde results. Efforts were made to obtain surface air pressure at GPS stations by combining ground GPS station meteorological pressure observations, nearby synoptic station records, and ERA-Interim products to ensure both high accuracy and completeness. For most stations, the 6-hourly integrated pressure measurements have been calculated or obtained for approximately $90 \%-100 \%$ of the site observations with an accuracy of about $0.7 \mathrm{hPa}$. PW estimates were then retrieved with 6-h interval for all GPS stations and the uncertainty of PW contributed by different factors was analyzed accordingly. Based on this error analysis, the mean PW error is approximately $0.75 \mathrm{~mm}$, with minimum and maximum errors of 0.55 and $1.10 \mathrm{~mm}$, respectively.

Radiosonde data suffer from changes in instruments, observational practice, processing strategies, station relocations, or other issues. Previous studies have focused on identifying and quantifying errors in Vaisala and VIZ radiosondes, which are typically deployed in the Western Hemisphere and Europe. There are only a few studies of radiosonde types deployed in China, and these used a small number of GPS stations, a limited length of GPS records, or other observations and methods which are also susceptible to inhomogeneity issues. Our PW estimates for over 260 stations covering the period from 1999 to 2015 provide a good opportunity to identify systematic errors in radiosondes used in China and their impacts in reanalyses. Because of incomplete documentation of radiosonde changes, we identified additional type changes and their timing through comparison of PW calculated from radiosonde and GPS data. This is the first work to describe the biases associated with all four types of sensors used in China, by distinguishing between the two radiosonde types Shang-M (GZZ2) and Shang-E (GTS1), and differences between GTS1-1 and GTS1-2. The radiosondes minus GPS PW differences were then analyzed separately for each of the four types (i.e., GZZ2, GTS1, GTS1-1, and GTS1-2). For GZZ2 equipped with the goldbeater's skin humidity sensor, there is a mean wet bias of approximately $1-2 \mathrm{~mm}$, with dry biases seen only at three stations above $2000 \mathrm{~m}$. An exception is that there are very large dry biases for observations with PW greater than $60 \mathrm{~mm}$. For GTS1 carrying a carbon hygristor, the radiosonde stations are found to have dry biases of approximately $1.2 \mathrm{~mm}$ in PW. The newly deployed GTS1-1 is also equipped with a carbon hygristor and has a better performance than GTS1, but still contains dry biases in PW $(\sim 0.4 \mathrm{~mm})$. There are slight wet biases $(\sim 0.3 \mathrm{~mm})$ in the newly deployed GTS1-2, which uses a thin-film capacitor as humidity sensor. The biases in different radiosonde types will introduce significant biases in PW trend estimates for stations where more than two types of sensor were used. GZZ2 radiosondes, containing significant wet biases for most stations, were widely used before being replaced by GTS1 with obvious dry biases, GTS1-1 with small dry biases, and GTS1-2 with slight wet biases. This produces artificially decreasing PW trends from the radiosonde data for most stations during 


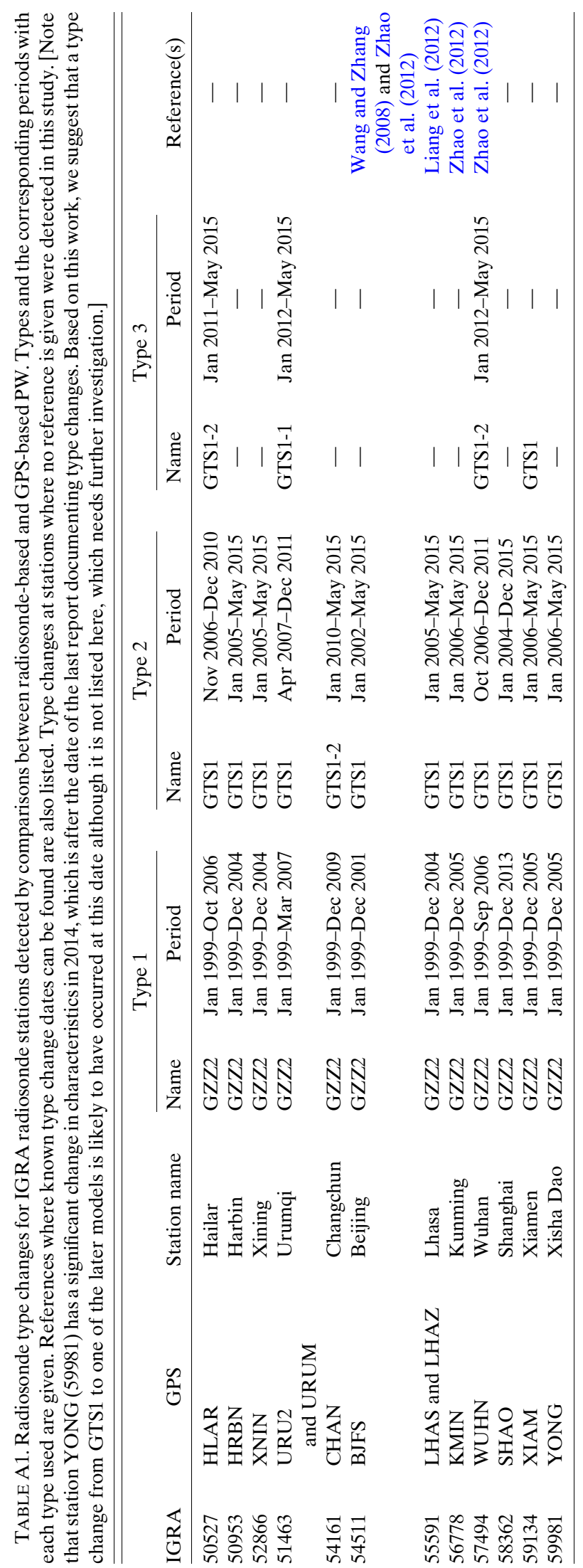


TABLE B1. Trend estimates based on GPS, radiosonde, and ERA-Interim PW at all stations with PW time series length longer than 9 yr. Numbers in boldface denote statistically significant estimates; numbers in parentheses denote estimates that are not statistically significant.

\begin{tabular}{|c|c|c|c|c|c|c|c|c|}
\hline \multirow[b]{2}{*}{ GPS (IGRA) station } & \multirow[b]{2}{*}{ Station elev (m) } & \multicolumn{3}{|c|}{$0000 \mathrm{UTC}\left(\mathrm{mm} \mathrm{yr}^{-1}\right)$} & \multicolumn{3}{|c|}{$1200 \mathrm{UTC}\left(\mathrm{mm} \mathrm{yr}^{-1}\right)$} & \multirow{2}{*}{$\frac{\text { All times }}{\text { GPS }}$} \\
\hline & & GPS & Radiosonde & ERA-Interim & GPS & Radiosonde & ERA-Interim & \\
\hline BJFS (54511) & 98.4 & $(0.023)$ & -0.049 & -0.053 & 0.060 & $(-0.037)$ & $-\mathbf{0 . 0 3 7}$ & 0.038 \\
\hline CHAN (54161) & 258.7 & $(0.016)$ & -0.078 & -0.021 & 0.052 & -0.032 & $(-0.012)$ & $(0.038)$ \\
\hline HLAR (50527) & 633.5 & $(-0.002)$ & -0.126 & $(-0.010)$ & 0.022 & -0.072 & $(-0.009)$ & $(0.004)$ \\
\hline HRBN (50953) & 184.5 & $(0.020)$ & $-\mathbf{0 . 1 0 2}$ & $(0.005)$ & 0.045 & -0.086 & $(0.010)$ & 0.035 \\
\hline KMIN (56778) & 2019.1 & 0.030 & -0.142 & $(-0.087)$ & 0.042 & -0.099 & -0.056 & $\mathbf{0 . 0 3 1}$ \\
\hline LHAS (55591) & 3659.3 & $(-0.006)$ & $-\mathbf{0 . 0 3 2}$ & $(-0.006)$ & $(-0.013)$ & $(-0.002)$ & $(-0.010)$ & $(-0.002)$ \\
\hline LHAZ (55591) & 3659.3 & $(-0.006)$ & $-\mathbf{0 . 0 3 2}$ & $(-0.006)$ & $(0.019)$ & $(-0.002)$ & $(-0.010)$ & $(-0.002)$ \\
\hline SHAO (58362) & 11.8 & $(0.050)$ & -0.097 & $(-0.025)$ & 0.070 & $-\mathbf{0 . 1 3 0}$ & $(-0.029)$ & $(0.035)$ \\
\hline URUM (51463) & 919.1 & 0.029 & -0.147 & -0.070 & 0.056 & -0.080 & -0.076 & 0.043 \\
\hline WUHN (57494) & 40.3 & $(0.052)$ & -0.195 & $-\mathbf{0 . 1 0 7}$ & 0.081 & $(-0.027)$ & -0.065 & 0.068 \\
\hline XIAA (57036) & 543.6 & $(-0.020)$ & $(0.039)$ & -0.095 & $(0.015)$ & $(-0.003)$ & -0.093 & $(-0.011)$ \\
\hline XIAM (59134) & 96.0 & $(-0.015)$ & -0.206 & $(-0.050)$ & $(0.023)$ & -0.247 & $(-0.042)$ & $(-0.006)$ \\
\hline XNIN (52866) & 2407.7 & $(0.020)$ & -0.082 & $(-0.006)$ & $(0.020)$ & -0.022 & $(0.002)$ & $(0.018)$ \\
\hline YONG (59981) & 7.4 & -0.120 & -0.460 & $(0.028)$ & $(-0.045)$ & -0.481 & $(0.038)$ & $(-0.079)$ \\
\hline BJSH & 165.0 & $-\mathbf{0 . 0 3 6}$ & - & -0.045 & $(-0.001)$ & - & -0.031 & $(-0.025)$ \\
\hline DLHA & 3006.3 & -0.021 & - & $(-0.009)$ & $(-0.006)$ & - & $(-0.012)$ & $(-0.017)$ \\
\hline DXIN & 1073.5 & -0.054 & - & -0.040 & -0.042 & - & -0.034 & $-\mathbf{0 . 0 5 0}$ \\
\hline GUAN & 37.7 & 0.124 & - & $(-0.043)$ & 0.155 & - & $(-0.059)$ & 0.120 \\
\hline JIXN & 45.0 & -0.032 & - & $(-0.018)$ & $(-0.019)$ & - & $(-0.018)$ & -0.028 \\
\hline LUZH & 338.8 & $(-0.014)$ & - & -0.073 & $(0.006)$ & - & -0.059 & $(-0.008)$ \\
\hline QION & 218.8 & $(-0.002)$ & - & $(0.012)$ & $(0.004)$ & - & $(0.033)$ & $(0.000)$ \\
\hline SUIY & 344.1 & -0.050 & - & $(0.000)$ & -0.026 & - & $(0.009)$ & -0.037 \\
\hline TAIN & 345.0 & $(0.021)$ & - & -0.057 & 0.065 & - & -0.038 & $(0.032)$ \\
\hline TASH & 3079.6 & $(0.005)$ & - & -0.015 & $(-0.007)$ & - & -0.025 & $(0.002)$ \\
\hline WUSH & 1440.7 & -0.034 & - & $(-0.003)$ & -0.023 & - & $(-0.014)$ & -0.023 \\
\hline XIAG & 2012.2 & $(-0.011)$ & - & -0.057 & $(0.013)$ & - & -0.043 & $(-0.005)$ \\
\hline YANC & 1340.7 & $(0.006)$ & - & -0.024 & 0.042 & - & $(-0.005)$ & $(0.017)$ \\
\hline ZHNZ & 464.3 & $(0.049)$ & - & $-\mathbf{0 . 1 1 0}$ & 0.050 & - & -0.117 & $(0.041)$ \\
\hline
\end{tabular}

the period from 1999 to 2015 , although the exact effect on the trend varies depending on the date of the change.

Similarly, the large GPS dataset in China also provides the possibility to independently evaluate water vapor information in reanalysis products. ERA-Interim, which is one of the most widely used new generation reanalysis products (Gregow et al. 2015), is chosen in this study. The biases in ERA-Interim PW relative to GPS PW are found to be smaller than $2 \mathrm{~mm}$ for most of stations and STD of PW differences range from about 1.5 to $3 \mathrm{~mm}$. The size of the mean relative PW differences are affected by station elevation, where PW is small (within approximately $-10 \%$ and $10 \%$ ) for stations below $1000 \mathrm{~m}$ but larger (reaching from $-20 \%$ to $50 \%$ ) for stations above $3000 \mathrm{~m}$. Relative STD are correlated with height, from about $5 \%-30 \%$ for low-elevation stations (below $2000 \mathrm{~m}$ ) to about $20 \%-50 \%$ for highelevation stations (above $2000 \mathrm{~m}$ ). The PW difference time series have seasonal variations. We found that the STDs of PW differences (ERA-Interim minus GPS) are largest $(\sim 2.7 \mathrm{~mm}$ or $\sim 11.8 \%)$ in the summer and smallest $(\sim 1.1 \mathrm{~mm}$ or $\sim 19.8 \%)$ in the winter. Regarding the PW trends, with the uncorrected radiosonde humidity data assimilated, ERA-Interim results show decreasing PW trends for almost all stations in China from 1999 to 2015. However, as shown in the homogeneous GPS PW results, there are a considerable number of stations showing increasing PW trends (mainly in eastern China) or insignificant trends during the same period. Evaluations of other reanalysis products, which is beyond the scope of this study, can be carried out in the same way as ERAInterim. Based on the study by Zhao et al. (2015) through comparisons with homogenized radiosonde dataset, the artificial decreasing PW trends found in ERA-Interim in this paper may also exist in most other reanalysis products, such as NCEP-NCAR, NCEP-DOE, JRA-25, JRA-55, and MERRA because of the assimilation of the similar unadjusted radiosonde humidity data over China. The new generation reanalysis, the NOAACIRES Twentieth Century Reanalysis (20CR), may be an exception because only surface observations were assimilated. However, these inferences need independent confirmation with the derived GPS PW dataset in the future work. 
There are still some limitations in the current GPS dataset used in this study. For example, the relative sparsity of the GPS station network in phase I in CMONOC before 2011 limits the spatial resolution of the long-term PW trend analysis. The absence of meteorological measurements at GPS stations in phase I is another limitation, and even in phase II there are periods when measurements are not complete enough for PW retrievals. However, results from this study could potentially be used to implement a bias correction scheme for radiosonde PW data. It provides motivation for a systematic approach to replacement or standardization of the radiosonde network, which could improve accuracy of reanalysis products over China. GPS PW datasets such as this one may also contribute to diagnosing diurnal and other biases in climate model precipitation (Dai 2006; Stephens et al. 2010) by providing high rate regionally dense measurements of moisture variations in China.

Acknowledgments. We thank the National Earthquake Infrastructure Service in China for providing the GPS data, the National Climatic Data Center of the National Oceanic and Atmospheric Administration for providing the IGRA radiosonde data and ISD surface synoptic data, and ECMWF for providing the ERA-Interim products. This work was supported by the National Key Research and Development Program of China (2016YFB0501800), the National Natural Science Foundation of China (Grant 41374034), and the Fundamental Research Funds for the Central Universities (2042017kf0179). One of the authors (W. Zhang) was supported by the China Scholarship Council (201406270066), which is gratefully acknowledged.

\section{APPENDIX A}

\section{List of Radiosonde Stations with Type Changes}

The list of IGRA radiosonde stations where more than one radiosonde type was used is given in Table A1. The dates of radiosonde type changes are identified by comparisons between radiosonde-based and GPS-based PW. References where known type change dates can be found are also given in Table A1.

\section{APPENDIX B}

\section{Trend Estimates Based on GPS, Radiosonde, and ERA-Interim PW}

The PW trend estimates for all GPS stations with observations longer than 9 years are presented in Table B1, together with the trend estimates based on radiosonde and ERA-Interim PW for the same period.

\section{REFERENCES}

Bannon, J. K., and L. P. Steel, 1960: Averaged water vapor contents of the air. Geophysical Memo. 102, Met Office M.O. 631b, $38 \mathrm{pp}$.

Bengtsson, L., S. Hagemann, and K. I. Hodges, 2004: Can climate trends be calculated from reanalysis data? J. Geophys. Res., 109, D11111, doi:10.1029/2004JD004536.

Bevis, M., S. Businger, T. A. Herring, C. Rocken, R. A. Anthes, and R. H. Ware, 1992: GPS meteorology: Remote sensing of the atmospheric water vapor using the Global Positioning System. J. Geophys. Res., 97, 15787-15801, doi:10.1029/ 92JD01517.

Boehm, J., A. Niell, P. Tregoning, and H. Schuh, 2006: Global Mapping Function (GMF): A new empirical mapping function based on numerical weather model data. Geophys. Res. Lett., 33, L07304, doi:10.1029/2005GL025546.

_ R. Heinkelmann, and H. Schuh, 2007: Short note: A global model of pressure and temperature for geodetic applications. J. Geod., 81, 679-683, doi:10.1007/s00190-007-0135-3.

Brenot, H., and Coauthors, 2014: A GPS network for tropospheric tomography in the framework of the Mediterranean hydrometeorological observatory Cévennes-Vivarais (southeastern France). Atmos. Meas. Tech., 7, 553-578, doi:10.5194/amt-7-553-2014.

Dai, A., 2006: Precipitation characteristics in eighteen coupled climate models. J. Climate, 19, 4605-4630, doi:10.1175/ JCLI3884.1.

- J. Wang, P. W. Thorne, D. E. Parker, L. Haimberger, and X. L. Wang, 2011: A new approach to homogenize daily radiosonde humidity data. J. Climate, 24, 965-991, doi:10.1175/ 2010JCLI3816.1.

Dee, D. P., and Coauthors, 2011: The ERA-Interim reanalysis: Configuration and performance of the data assimilation system. Quart. J. Roy. Meteor. Soc., 137, 553-597, doi:10.1002/ qj.828.

Deeter, M. N., 2007: A new satellite retrieval method for precipitable water vapor over land and ocean. Geophys. Res. Lett., 34, L02815, doi:10.1029/2006GL028019.

Dessler, A. E., and S. M. Davis, 2010: Trends in tropospheric humidity from reanalysis systems. J. Geophys. Res., 115, D19127, doi:10.1029/2010JD014192.

Ding, Y., 1994: Monsoons over China. Springer, 432 pp.

Divakarla, M. G., C. D. Barnet, M. D. Goldberg, L. M. McMillin, E. Maddy, W. Wolf, L. Zhou, and X. Liu, 2006: Validation of Atmospheric Infrared Sounder temperature and water vapor retrievals with matched radiosonde measurements and forecasts. J. Geophys. Res., 111, D09S15, doi:10.1029/2005JD006116.

Durre, I., R. S. Vose, and D. B. Wuertz, 2006: Overview of the Integrated Global Radiosonde Archive. J. Climate, 19, 53-68, doi:10.1175/JCLI3594.1.

— C. N. Williams Jr., X. Ying, and R. S. Vose, 2009: Radiosondebased trends in precipitable water over the Northern Hemisphere: An update. J. Geophys. Res., 114, D05112, doi:10.1029/2008JD010989.

Easterling, D. R., and T. C. Peterson, 1995: A new method for detecting and adjusting for undocumented discontinuities in climatological time series. Int. J. Climatol., 15, 369-377, doi:10.1002/joc.3370150403. 
Elgered, G., J. L. Davis, T. A. Herring, and I. I. Shapiro, 1991: Geodesy by radio interferometry: Water vapor radiometry for estimation of the wet delay. J. Geophys. Res., 96, 6541-6555, doi:10.1029/90JB00834.

—_ J. Johansson, B. Rönnäng, and J. Davis, 1997: Measuring regional atmospheric water vapor using the Swedish Permanent GPS Network. Geophys. Res. Lett., 24, 2663-2666, doi:10.1029/97GL02798.

Elliott, W. P., and D. J. Gaffen, 1991: On the utility of radiosonde humidity archives for climate studies. Bull. Amer. Meteor. Soc., 72, 1507-1520, doi:10.1175/1520-0477(1991)072<1507: OTUORH $>2.0 . \mathrm{CO} ; 2$.

Emardson, T. R., G. Elgered, and J. M. Johansson, 1998: Three months of continuous monitoring of atmospheric water vapor with a network of GPS receivers. J. Geophys. Res., 103, 18071820, doi:10.1029/97JD03015.

Fan, J. Q., and Q. W. Yao, 2003: Nonlinear Time Series: Nonparametric and Parametric Methods. Springer, $553 \mathrm{pp}$.

Gendt, G., G. Dick, C. H. Reigber, M. Tomassini, Y. Liu, and M. Ramatschi, 2003: Demonstration of NRT GPS water vapor monitoring for numerical weather prediction in Germany. J. Meteor. Soc. Japan, 82, 360-370.

Gregow, H., and Coauthors, 2015: User awareness concerning feedback data and input observations used in reanalysis systems. Adv. Sci. Res., 12, 63-67, doi:10.5194/asr-12-63-2015.

Haase, J. S., M. Ge, H. Vedel, and E. Calais, 2003: Accuracy and variability of GPS tropospheric delay measurements of water vapor in the western Mediterranean. J. Appl. Meteor., 42, 1547-1568, doi:10.1175/1520-0450(2003)042<1547: AAVOGT $>2.0 . \mathrm{CO} ; 2$.

Hagemann, S., L. Bengtsson, and G. Gendt, 2003: On the determination of atmospheric water vapor from GPS measurements. J. Geophys. Res., 108, 4678, doi:10.1029/2002JD003235.

Hajj, G. A., and Coauthors, 2004: CHAMP and SAC-C atmospheric occultation results and intercomparisons. J. Geophys. Res., 109, D06109, doi:10.1029/2003JD003909.

Ho, S.-P., X. Zhou, Y.-H. Kuo, D. Hunt, and J. Wang, 2010: Global evaluation of radiosonde water vapor systematic biases using GPS radio occultation from COSMIC and ECMWF analysis. Remote Sens., 2, 1320-1330, doi:10.3390/rs2051320.

IPCC, 1996: Climate Change 1995: The Science of Climate Change. Cambridge University Press, $572 \mathrm{pp}$.

Jade, S., and M. S. M. Vijayan, 2008: GPS-based atmospheric precipitable water vapor estimation using meteorological parameters interpolated from NCEP global reanalysis data. J. Geophys. Res., 113, D03106, doi:10.1029/ 2007JD008758.

Jin, S., J.-U. Park, J.-H. Cho, and P.-H. Park, 2007: Seasonal variability of GPS-derived zenith tropospheric delay (1994-2006) and climate implications. J. Geophys. Res., 112, D09110, doi:10.1029/2006JD007772.

_ Z Z. Li, and J. Cho, 2008: Integrated water vapor field and multiscale variations over China from GPS measurements. J. Appl. Meteor. Climatol., 47, 3008-3015, doi:10.1175/ 2008JAMC1920.1.

Kendall, M. G., 1975: Rank Correlation Methods. Charles Griffin, $202 \mathrm{pp}$

Kiehl, J. T., and K. E. Trenberth, 1997: Earth's annual global mean energy budget. Bull. Amer. Meteor. Soc., 78, 197-208, doi:10.1175/1520-0477(1997)078<0197:EAGMEB>2.0.CO;2.

Lau, K.-M., 1992: East Asian summer monsoon rainfall variability and climate teleconnection. J. Meteor. Soc. Japan, 70, 211-242, doi:10.2151/jmsj1965.70.1B_211.
Li, W., 2010: The performance assessment of Chinese GTS1 radiosonde measurements. TECO-2010-WMO Technical Conf. on Meteorological and Environmental Instruments and Methods of Observation, Helsinki, Finland, WMO. [Available online at http://www.wmo.int/pages/prog/www/IMOP/publications/IOM104_TECO-2010/_PROGRAMME.HTML.]

Liang, H., R. Zhang, and J. Liu, 2012: Systematic errors in the precipitable water vapor measurements over the Tibetan Plateau and its causes (in Chinese). Acta Meteor. Sin., 70, 155164.

Liou, Y. A., A. G. Pavelyev, J. Wickert, T. Schmidt, and A. A. Pavelyev, 2005: Analysis of atmospheric and ionospheric structures using the GPS/MET and CHAMP radio occultation database: A methodological review. GPS Solut., 9, 122-143, doi:10.1007/s10291-005-0141-y.

Liu, J., Z. Sun, H. Liang, X. Xu, and P. Wu, 2005: Precipitable water vapor on the Tibetan Plateau estimated by GPS, water vapor radiometer, radiosonde, and numerical weather prediction analysis and its impact on the radiation budget. J. Geophys. Res., 110, D17106, doi:10.1029/2004JD005715.

Liu, Z., A. Mehran, T. J. Phillips, and A. AghaKouchak, 2014: Seasonal and regional biases in CMIP5 precipitation simulations. Climate Res., 60, 35-50, doi:10.3354/cr01221.

Mann, H. B., 1945: Nonparametric tests against trend. Econometrica, 13, 245-259, doi:10.2307/1907187.

Miloshevich, L. M., H. Vömel, A. Paukkunen, A. J. Heymsfield, and S. J. Oltmans, 2001: Characterization and correction of relative humidity measurements from Vaisala RS80-A radiosondes at cold temperatures. J. Atmos. Oceanic Technol., 18, 135-156, doi:10.1175/1520-0426(2001)018<0135: $\mathrm{CACORH}>2.0 . \mathrm{CO} ; 2$.

Nilsson, T., and G. Elgered, 2008: Long-term trends in the atmospheric water vapor content estimated from ground-based GPS data. J. Geophys. Res., 113, D19101, doi:10.1029/ 2008JD010110.

Ning, T., and Coauthors, 2016: The uncertainty of the atmospheric integrated water vapour estimated from GNSS observations. Atmos. Meas. Tech., 9, 79-92, doi:10.5194/amt-9-79-2016.

Parker, D. E., and D. I. Cox, 1995: Towards a consistent global climatological rawinsonde data-base. Int. J. Climatol., 15, 473496, doi:10.1002/joc.3370150502.

Poli, P., and Coauthors, 2007: Forecast impact studies of zenith total delay data from European near real-time GPS stations in Météo France 4DVAR. J. Geophys. Res., 112, D06114, doi:10.1029/2006JD007430.

Rebischung, P., J. Griffiths, J. Ray, R. Schmid, X. Collilieux, and B. Garayt, 2012: IGS08: The IGS realization of ITRF2008. GPS Solut., 16, 483-494, doi:10.1007/s10291-011-0248-2.

Rocken, C., T. Van Hove, J. Johnson, F. Solheim, R. Ware, M. Bevis, S. Chiswell, and S. Businger, 1995: GPS/STORMGPS sensing of atmospheric water vapor for meteorology. J. Atmos. Oceanic Technol., 12, 468-478, doi:10.1175/ 1520-0426(1995)012<0468:GSOAWV>2.0.CO;2.

Ross, R. J., and W. P. Elliott, 2001: Radiosonde-based Northern Hemisphere tropospheric water vapor trends. J. Climate, 14, 1602-1612, doi:10.1175/1520-0442(2001)014<1602: RBNHTW $>2.0 . \mathrm{CO} ; 2$.

Saastamoinen, J., 1972: Atmospheric correction for the troposphere and stratosphere in radio ranging satellites. The Use of Artificial Satellites for Geodesy, Geophys. Monogr., Vol. 15, Amer. Geophys. Union, 247-251, doi:10.1029/GM015p0247.

Santer, B. D., and Coauthors, 2006: Forced and unforced ocean temperature changes in Atlantic and Pacific tropical cyclogenesis 
regions. Proc. Natl. Acad. Sci. USA, 103, 13905-13910, doi:10.1073/pnas.0602861103.

Schaer, S., and P. Steigenberger, 2006: Determination and use of GPS differential code bias values. IGS Workshop 2006, International GNSS Service, Darmstadt, Germany. [Available online at kb.igs.org/hc/en-us/articles/202111816-IGS-Workshop-2006-Website.]

Schmid, R., P. Steigenberger, G. Gendt, M. Ge, and M. Rothacher, 2007: Generation of a consistent absolute phase-center correction model for GPS receiver and satellite antennas. J. Geod., 81, 781-798, doi:10.1007/s00190-007-0148-y.

Sen, P. K., 1968: Estimates of the regression coefficient based on Kendall's tau. J. Amer. Stat. Assoc., 63, 1379-1389, doi:10.1080/ 01621459.1968.10480934.

Shi, C., Q. Zhao, J. Geng, Y. Lou, M. Ge, and J. Liu, 2008: Recent development of PANDA software in GNSS data processing. International Conference on Earth Observation Data Processing and Analysis (ICEODPA), D. Li, J. Gong, and H. Wu, Eds., International Society for Optical Engineering (SPIE Proceedings, Vol. 7285), doi:10.1117/12.816261.

Smith, T. L., S. G. Benjamin, B. E. Schwartz, and S. I. Gutman, 2000: Using GPS-IPW in a 4-D data assimilation system. Earth Planets Space, 52, 921-926, doi:10.1186/BF03352306.

Soden, B., R. Wetherald, G. Stenchikov, and A. Robock, 2002: Global cooling after the eruption of Mount Pinatubo: A test of climate feedback by water vapor. Science, 296, 727-730, doi:10.1126/science.296.5568.727.

Stephens, G. L., and Coauthors, 2010: Dreary state of precipitation in global models. J. Geophys. Res., 115, D24211, doi:10.1029/ 2010JD014532.

Sun, B., A. Reale, S. Schroeder, D. J. Seidel, and B. Ballish, 2013: Toward improved corrections for radiation-induced biases in radiosonde temperature observations. J. Geophys. Res. Atmos., 118, 4231-4243, doi:10.1002/jgrd.50369.

Sun, J., 1993: Effects of vertical distribution of water vapor and temperature on total column water vapor retrieval error. J. Geophys. Res., 98, 7069-7079, doi:10.1029/93JC00010.

Takagi, T., F. Kimura, and S. Kono, 2000: Diurnal variation of GPS precipitable water at Lhasa in premonsoon and monsoon periods. J. Meteor. Soc. Japan, 78, 175-180, doi:10.2151/ jmsj1965.78.2_175.

Trenberth, K. E., R. M. Rasmussen, and D. B. Parsons, 2003: The changing character of precipitation. Bull. Amer. Meteor. Soc., 84, 1205-1217, doi:10.1175/BAMS-84-9-1205.

Vedel, H., X.-Y. Huang, J. Haase, M. Ge, and E. Calais, 2004: Impact of GPS zenith tropospheric delay data on precipitation forecasts in Mediterranean France and Spain. Geophys. Res. Lett., 31, L02102, doi:10.1029/2003GL017715.

Vey, S., R. Dietrich, M. Fritsche, A. Rülke, P. Steigenberger, and M. Rothacher, 2009: On the homogeneity and interpretation of precipitable water time series derived from global GPS observations. J. Geophys. Res., 114, D10101, doi:10.1029/ 2008JD010415.

-, —, A. Rülke, M. Fritsche, P. Steigenberger, and M. Rothacher, 2010: Validation of precipitable water vapor within the NCEP/DOE reanalysis using global GPS observations from one decade. J. Climate, 23, 1675-1695, doi:10.1175/ 2009JCLI2787.1.
Vömel, H., and Coauthors, 2007: Radiation dry bias of the Vaisala RS92 humidity sensor. J. Atmos. Oceanic Technol., 24, 953963, doi:10.1175/JTECH2019.1.

Wang, B., R. Wu, and X. Fu, 2000: Pacific-East Asian teleconnection: How does ENSO affect East Asian climate? J. Climate, 13, 1517-1536, doi:10.1175/1520-0442(2000)013<1517: PEATHD $>2.0 . \mathrm{CO} ; 2$.

Wang, J., and L. Zhang, 2008: Systematic errors in global radiosonde precipitable water data from comparisons with groundbased GPS measurements. J. Climate, 21, 2218-2238, doi:10.1175/2007JCLI1944.1.

, D. J. Carlson, D. B. Parsons, T. F. Hock, D. Lauritsen, H. L. Cole, K. Beierle, and E. Chamberlain, 2003: Performance of operational radiosonde humidity sensors in direct comparison with a chilled mirror dew-point hygrometer and its climate implication. Geophys. Res. Lett., 30, 1860, doi:10.1029/ 2003GL016985.

—- L. Zhang, and A. Dai, 2005: Global estimates of watervapor-weighted mean temperature of the atmosphere for GPS applications. J. Geophys. Res., 110, D21101, doi:10.1029/2005JD006215.

- — , and - 2006: A global, 2-hourly atmospheric precipitable water dataset from IGS ground-based GPS measurements: Scientific applications and future needs. IGS Workshop 2006, Darmstadt, Germany, International GNSS Service. [Available online at kb.igs.org/hc/en-us/articles/ 202111816-IGS-Workshop-2006-Website.]

$,-\ldots,-$, T. Van Hove, and J. Van Baelen, 2007: A nearglobal, 8-year, 2-hourly data set of atmospheric precipitable water from ground-based GPS measurements. J. Geophys. Res., 112, D11107, doi:10.1029/2006JD007529.

WMO, 2014: Observing stations and WMO catalogue of radiosondes. WMO Publ. 9, Vol. A, 602 pp. [Available online at http://www.wmo.int/pages/prog/www/ois/volume-a/vola-home. htm.]

Wu, J., S. Wu, G. Hajj, W. Bertiger, and S. Lichten, 1993: Effect of antenna orientation on GPS carrier phase. Manuscripta Geodaetica, 18, 91-98.

Zhai, P., and R. E. Eskridge, 1996: Analysis of inhomogeneities in radiosonde temperature and humidity time series. J. Climate, 9, 884-894, doi:10.1175/1520-0442(1996)009<0884: AOIIRT $>2.0 . \mathrm{CO} ; 2$.

— and - 1997: Atmospheric water vapor over China. J. Climate, 10, 2643-2652, doi:10.1175/1520-0442(1997)010<2643: AWVOC $>2.0 . C O ; 2$.

Zhao, T., A. Dai, and J. Wang, 2012: Trends in tropospheric humidity from 1970 to 2008 over China from a homogenized radiosonde dataset. J. Climate, 25, 4549-4567, doi:10.1175/ JCLI-D-11-00557.1.

— J. Wang, and A. Dai, 2015: Evaluation of atmospheric precipitable water from reanalysis products using homogenized radiosonde observations over China. J. Geophys. Res. Atmos., 120, $10703-10727$, doi:10.1002/2015JD023906.

Zumberge, J. F., M. B. Heflin, D. C. Jefferson, M. M. Watkins, and F. H. Webb, 1997: Precise point positioning for the efficient and robust analysis of GPS data from large networks. J. Geophys. Res., 102, 5005-5017, doi:10.1029/96JB03860. 